\title{
Orfebrería castreña en el Museo Arqueológico de Asturias (Oviedo): aproximación a su caracterización arqueométrica y problemas de estudio*
}

\author{
Castro Culture gold objects from the archaeological museum of Asturias (Oviedo): an \\ approach to their archaeometric characterization and to the complexities of their study
}

\author{
Óscar García-Vueltaa ${\text { Ignacio Montero Ruiz }{ }^{\mathrm{a}} \text { y Ángel Villa Valdés }}^{\mathrm{b}}$
}

\begin{abstract}
RESUMEN
Se presentan los resultados de la revisión de un grupo de piezas de orfebrería castreña de la II Edad del Hierro conservadas en el Museo Arqueológico de Asturias, que en su mayor parte permanecían insuficientemente estudiadas desde el punto de vista documental y arqueométrico. Este trabajo, centrado principalmente en el análisis no destructivo y la revisión topográfica de los objetos, aporta nuevos datos sobre su tecnología de elaboración. Destaca la identificación de nuevos ejemplos de aplicación de dorado por amalgama de mercurio. La labor realizada supone también un buen ejemplo de las dificultades existentes para el estudio de este tipo de materiales.
\end{abstract}

\begin{abstract}
We present the results of an examination of a group of gold-work from the Later Iron Age "Castro Culture" in the Archeological Museum of Asturias that was insufficiently studied from a documental and archaeometric point of view. Our work centered mainly on non-destructive analyses and the topographic revision of these objects and has allowed us to obtain new information regarding their production technology. We highlight the identification of new examples of mercury gilding. Our work also illustrates the difficulties surrounding the study of these types of objects.
\end{abstract}

Palabras clave: II Edad del Hierro; Noroeste de la península ibérica; Cultura castreña; Arqueometría; Análisis por fluorescencia de rayos-X (XRF); Torques; Dorado por amalgama de mercurio.

Key words: Later Iron Age; NW Iberian Peninsula; Castro culture; Archaeometry; XRF analysis; Torcs; Fire gilding.

\section{INTRODUCCIÓN}

La colección de orfebrería prehistórica y protohistórica del Museo Arqueológico de Asturias (MAA), heredero del antiguo Museo Provincial de Oviedo (Fernández de Córdoba 2017), se inició entre finales del siglo XIX y principios del XX. Está integrada en su mayor parte por objetos de oro que han tenido una desigual atención en la investigación, primando la dedicada a tres piezas que corresponden a las primeras etapas metalúrgicas. La primera es el "anillo de tiras" de oro (MAA 03256) descubierto en las excavaciones del dolmen de Mata l'Casare I, en la necrópolis de La Cobertoria (Quirós) (Blas Cortina 1994, 2013: 107109; Villa 2019: 28-29). Las otras son un par de discos laminares con decoración repujada de supuesta procedencia del occidente de Asturias (MAA 03257 y 03258), que pertenecen a un tipo que cuenta con paralelos formales en el ámbito atlántico. Interpretados como adorno de vestuario son el más antiguo testimonio de la metalurgia del oro en Asturias (Mac White 1951: 50; Blas Cortina, 1983: 128-130; Hernando

\footnotetext{
* Este estudio se integra en el Proyecto: "Paisajes rurales antiguos en el Noroeste peninsular: formas de dominación y explotación de recursos" (HAR2015-64632-P; MINECO-FEDER), cuya Investigadora Principal es Inés Sastre Prats (Instituto de Historia, CSIC, Madrid).

${ }^{a}$ Instituto de Historia (CSIC). C/Albasanz 26-28. 28037 Madrid. Correos e.: oscar.gvuelta@cchs.csic.es https://orcid.org/0000-0002-4032-569X; ignacio.montero@cchs.csic.es https://orcid.org/0000-0003-0897-1031

b Museo Arqueológico de Asturias. Principado de Asturias. C/San Vicente 3. 33003 Oviedo. Correo e.: angel.villavaldes@asturias.org https://orcid.org/0000-0002-9501-3749

Recibido: 26-III-2020. Aceptado: 30-IV-2020.
}

Copyright: (C) 2020 CSIC. Este es un artículo de acceso abierto distribuido bajo los términos de la licencia de uso y distribución "Creative Commons Reconocimiento 4.0 Internacional" (CC BY 4.0) 
1983: 113-114; Perea y Sánchez-Palencia 1995: 17-18; Fernández Moreno et al. 2018).

Las ocho piezas que estudiamos (Tab. 1) corresponden a la denominada "cultura castreña" y en su conjunto pueden fecharse en una fase avanzada de la II Edad del Hierro en estos territorios (ca. siglo II-I a. n. e. - I d. n. e.). Tres de ellas se localizaron en excavaciones arqueológicas en castros asturianos (Fig. 1). Las restantes son hallazgos antiguos al parecer producidos en Asturias, pero cuyo contexto o lugar exacto de recuperación, así como los datos precisos sobre su biografía reciente o sus circunstancias de ingreso en el museo se desconocen (Escortell 1982: 8384; Maya 1988: 141).

Esta falta de información ha contribuido a que hayan sido poco consideradas en la investigación y a la publicación de algunos datos erróneos. Sin embargo, el escaso número de piezas de orfebrería castreña referenciado en la región cantábrica (Maya 1988), así como la discusión en torno al significado cronológico y social de estas producciones (p. ej. González 2006-2007; Sastre 2008; Armada y GarcíaVuelta 2015, 2018; Parcero et al. 2017; Currás 2019: 302) aconsejaban integrar su estudio en la investigación más amplia en curso sobre la orfebrería castreña en Asturias.

Este trabajo supone una aportación en ese sentido y presenta un catálogo actualizado de los materiales, combinando su revisión formal y tecnológica a partir de la utilización de procedimientos no destructivos de caracterización arqueométrica. Como consecuencia se precisa la tipología de las piezas y se señalan algunas cuestiones de interés relativas a la tecnología orfebre en el ámbito castreño. Como complemento, se aporta información inédita a partir de fuentes documentales que contribuyen al estudio de los hallazgos antiguos incluidos en esta colección.

\section{METODOLOGÍA}

La revisión topográfica y analítica de la colección se efectuó en 2016 en los laboratorios de arqueología del Instituto de Historia (CSIC, Madrid) tras examinar las publicaciones sobre la misma y algunos testimonios documentales inéditos.

En el estudio formal de las piezas se utilizó una lupa binocular óptica (X60) para definir sus principales técnicas de fabricación y alteraciones. Los resultados se documentaron con fotografía macro digital y las dimensiones y pesos de los materiales se registraron con calibre y balanza de precisión.

El estudio arqueométrico se atuvo a los criterios marcados en la autorización de investigación, que excluía la manipulación en la superficie de los objetos. Esa circunstancia ha condicionado los métodos aplicables y los resultados finales obtenidos. Para la caracterización elemental básica de las piezas recurrimos a la técnica de espectroscopía de Fluorescencia de rayos-X (X-ray Flourescence Spectroscopy $-X R F-)$, empleándose un espectrómetro portátil (Portable $X$-ray Flourescence Spectroscopy - $p X R F-$-) Innov-X systems, serie Alpha, perteneciente al Museo Arqueológico Nacional. El aparato incorpora un tubo de rayos-X $\mathrm{y}$ ánodo de plata y fue previamente calibrado para el estudio de aleaciones metálicas. Los espectros se ob-

\begin{tabular}{|c|c|c|c|c|c|}
\hline Inventario & Tipo & Procedencia & $\begin{array}{l}\text { Dimensiones } \\
\text { (cm) }\end{array}$ & $\begin{array}{c}\text { Peso } \\
\text { (g) }\end{array}$ & Comentario \\
\hline MAA 03671 & Cadenilla & C. Chao Samartín & $15,7 \times 0,15$ & 2,85 & Incompleta \\
\hline MAA 08025 & Pendiente & C. Picu Castiellu & $2,3 \times 2,1 \times 0,47$ & 6,2 & Completo \\
\hline $\begin{array}{c}\text { MAA } 06670 \\
(a, b)\end{array}$ & $\begin{array}{l}\text { Láminas } \\
\text { decoradas }\end{array}$ & C. Llagú & $2 \times 0,008,0,009$ & 0,22 & 2 fragmentos, pesan 0,096 y $0,129 \mathrm{~g}$. \\
\hline MAA 06643 & $\begin{array}{l}\text { Torques } \\
\text { (aro incompleto) }\end{array}$ & Asturias & $13 \times 9,69 \times 0,4$ & 100,66 & Incompleto. Alteración moderna \\
\hline MAA 03540 & $\begin{array}{l}\text { Torques con } \\
\text { terminales } \\
\text { angulares }\end{array}$ & Asturias & $\begin{array}{l}\text { Aro: ca. } 16 \text { X ca. } \\
0,8 \text {. Terminales: } 4 \text {, } \\
3 \times 2,45\end{array}$ & 123,95 & \multirow{4}{*}{$\begin{array}{l}\text { Incompletas. } \\
\text { Reconstitución moderna. Peso y } \\
\text { dimensiones actuales }\end{array}$} \\
\hline MAA 03300 & $\begin{array}{l}\text { Torques con } \\
\text { terminales } \\
\text { incompletos }\end{array}$ & Asturias & $\begin{array}{l}\text { Aro: ca. } 16,5 \mathrm{X} \\
\text { ca. } 0,8\end{array}$ & 89,43 & \\
\hline MAA 03298 & Disco decorado 1 & Asturias & $5 \times 1$ & 8,33 & \\
\hline MAA 03299 & Disco decorado 2 & Asturias & $5,5, \times 1,3$ & 15,32 & \\
\hline
\end{tabular}

Tab.1. Datos básicos de las piezas del Museo Arqueológico de Asturias estudiadas. C Castro.

Trab. Prehist., 77, N. ${ }^{\circ}$ 1, enero-junio 2020, pp. 163-183, ISSN: 0082-5638

https://doi.org/10.3989/tp.2020.12252 


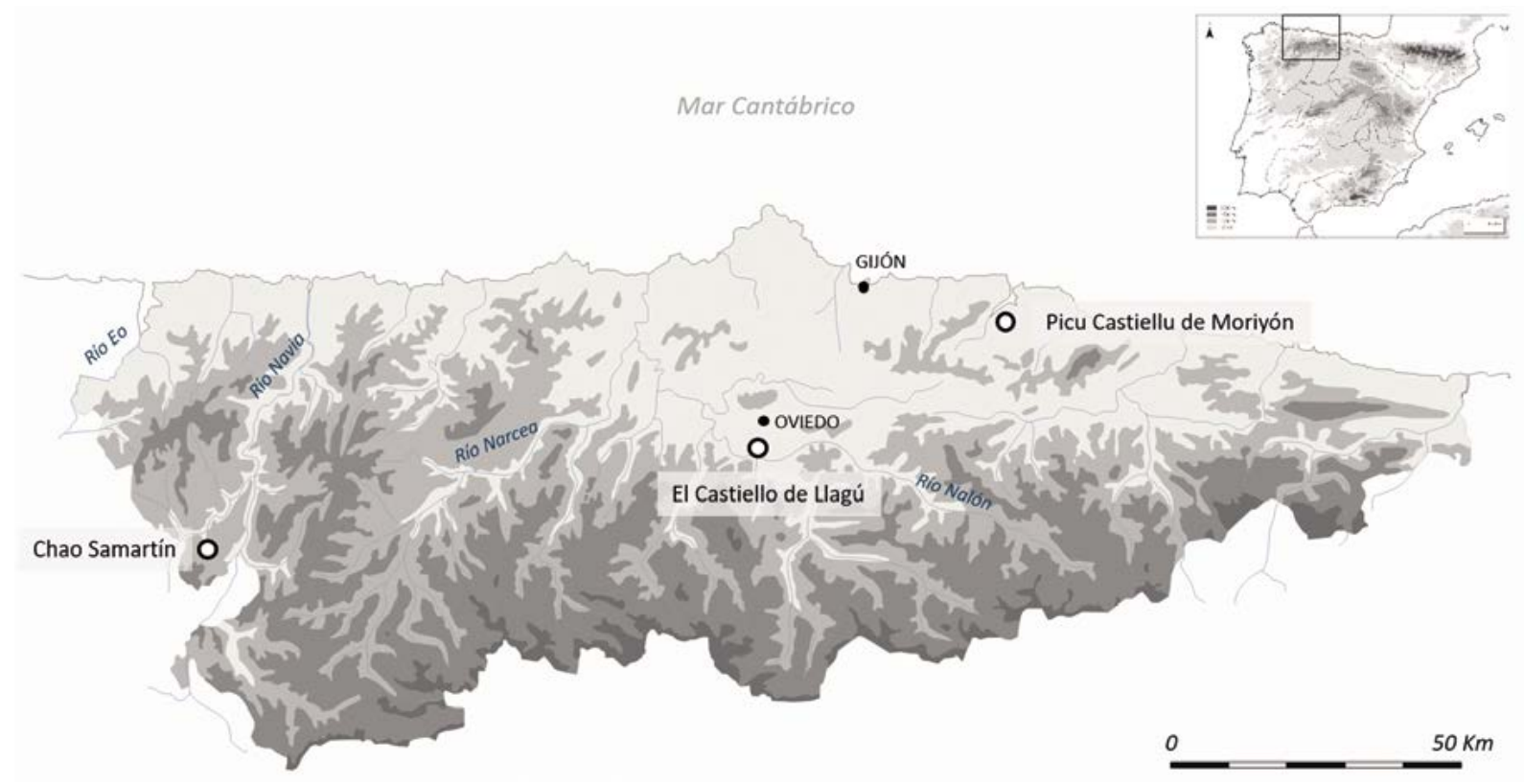

Fig. 1. Situación de Asturias en la península ibérica con localización de los objetos estudiados con datos de procedencia. Elaboración Ángel Villa Valdés.

tuvieron en soporte de seguridad, a un voltaje de 35 $\mathrm{KeV}$, con tiempos de captura de 40 segundos ${ }^{1}$.

Los análisis pXRF aportaron los datos semi-cuantitativos básicos sobre la composición de los materiales. Sin embargo, en ciertos casos, el tamaño de la ventana del espectrómetro -ca. $1 \mathrm{~cm}$ - no permitió la caracterización individualizada de algunos elementos estructurales u ornamentales, como hilos o glóbulos. Para completar el estudio algunos objetos fueron revisados mediante microscopía electrónica de barrido (Scanning Electron Microscopy -SEM-), en combinación con microanálisis por energía dispersiva de rayos-X (Energy Dispersive X-ray Spectroscopy-EDX-). Se empleó un SEM de presión variable Hitachi S3400n (Type II), provisto con detectores de electrones secundarios (Secondary Electrons $-S E-$ ), electrones retrodispersados (Backscattered Electrons $-B S E-$ ) y un espectrómetro EDX Bruker XFlash 4010 de tipo SDD. Los espectros EDX se obtuvieron a voltajes de 20 y $30 \mathrm{KeV}$ y los resultados se contrastaron mediante patrones virtuales de referencia, empleándose el software Bruker Sprit.

Hay que advertir que la aplicación de un producto de conservación no conductor a las piezas limitó a la inspección topográfica de las zonas menos afectadas

\footnotetext{
${ }^{1}$ Los resultados se procesaron con software Innov-X. Los límites de detección de los diferentes elementos analizados se sitúan en el 0,15 $\%$ para plata $(\mathrm{Ag})$ y estaño $(\mathrm{Sn})$ y $0,05 \%$ para los demás $(\mathrm{Fe}, \mathrm{Ni}, \mathrm{Cu}$, $\mathrm{As}, \mathrm{Au}, \mathrm{Pb}, \mathrm{Bi})$. Las características del equipo pXRF empleado se describen con más detalle en Rovira y Montero Ruiz 2018.
}

por el consolidante las posibilidades de trabajar con ellas en el SEM. En otros casos, el tamaño o la geometría de los objetos tampoco permitieron un correcto estudio con este procedimiento.

Los resultados analíticos que presentamos se apoyan en las informaciones obtenidas mediante pXRF y SEM-EDX pero es importante aclarar que, por factores como su resolución o su capacidad de penetración en la muestra, los valores cuantitativos recogidos con ambas técnicas no son directamente equiparables. Teniendo esto en cuenta, debe considerarse como información básica la obtenida mediante $\mathrm{pXRF}$, al aportar una mayor precisión cuantitativa y estar potencialmente menos afectada por fenómenos de alteración superficial (v. infra).

\section{CATÁllogo}

Las piezas se han organizado atendiendo a sus contextos de procedencia: excavaciones arqueológicas y hallazgos antiguos.

\subsection{Piezas localizadas en excavaciones arqueológicas}

Consisten en un fragmento de cadenilla, un pendiente y varios fragmentos laminares decorados. 
1. La cadenilla, de oro, procede del castro de Chao Samartín, Grandas de Salime (MAA 03671). Tiene sección rectangular y probablemente perteneció al sistema de suspensión de una arracada (Fig. 2: 1). Corresponde a la variante "doble" del tipo denominado loop-in-loop (Reist y Reist 2007) y se elaboró mediante el entrelazado de eslabones de hilo que presentan sus extremos unidos por soldadura (Fig. 3: 1). Estos hilos se obtuvieron a partir de la torsión de tiras laminares, procedimiento que dejó unas características huellas helicoidales en su superficie (Fig. 3: 2) (Villa 2004: 263, 2019: 37; Perea et al. 2010: 358, 363).

El fragmento se recuperó en 1994, en una calle abierta hacia la vía principal del castro. Su contexto de deposición se ha fechado entre los siglos I-II (Villa 2004: 262-263, 2009: 234, 2010: 119, 2019: 37), aunque se ha defendido su posible filiación prerromana (Hevia 1995: 269). Este tipo de cadenas de origen mediterráneo es conocido en la península ibérica desde el período orientalizante y cuenta con buenos paralelos en la orfebrería castreña. Se documentan principalmente en el grupo de las arracadas (Pérez Outeiriño 1982), aunque también en colgantes compuestos con procedencia asturiana (López Cuevillas 1951: 66, 90-91; Blanco 1957: 22-28; Maya 1988: 126 y 130; García-Vuelta 2017, 2018).

2. El pendiente de oro fusiforme de extremos apuntados recuperado en el castro de Picu Castiellu, Moriyón, Villaviciosa (MAA 08025) está completo, aunque ligeramente deformado (Fig. 2: 2). Integra un cuerpo macizo de sección romboidal con aristas marcadas de superficie redondeada y facetas ligeramente cóncavas (Fig. 3: 3-4). Sus extremos actuaron probablemente como un sistema de cierre por pinzamiento.

Se ha asociado con la segunda fase de ocupación del castro (Camino 1995a: 119), fechándose entre los
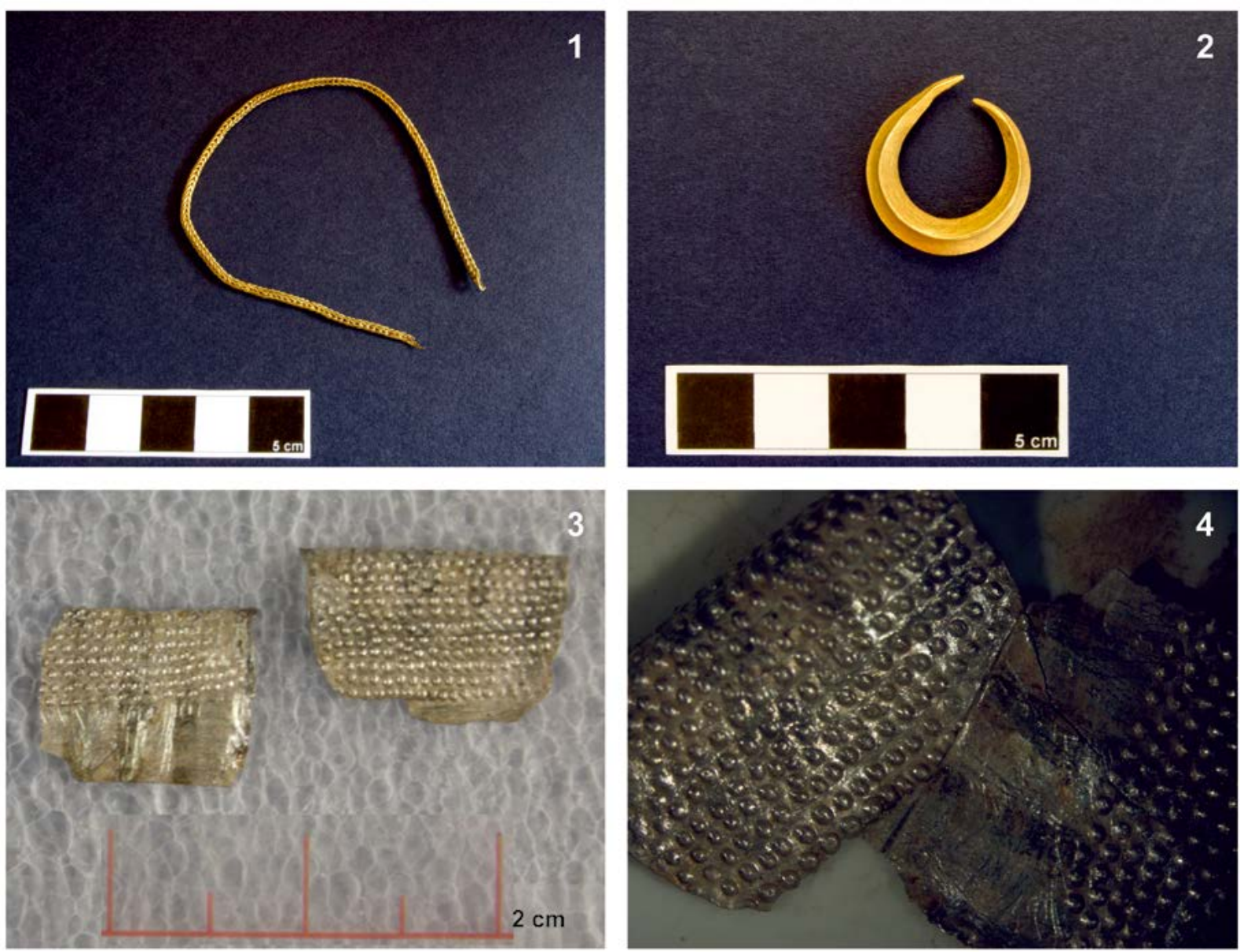

Fig. 2. Objetos del Museo Arqueológico de Asturias recuperados en excavaciones arqueológicas: 1. cadenilla de Chao Samartín; 2. pendiente de Picu Castiellu; 3-4. fragmentos laminares de Llagú. Fotos 1-2: Óscar García Vuelta; 3-4: Ángel Villa Valdés. 

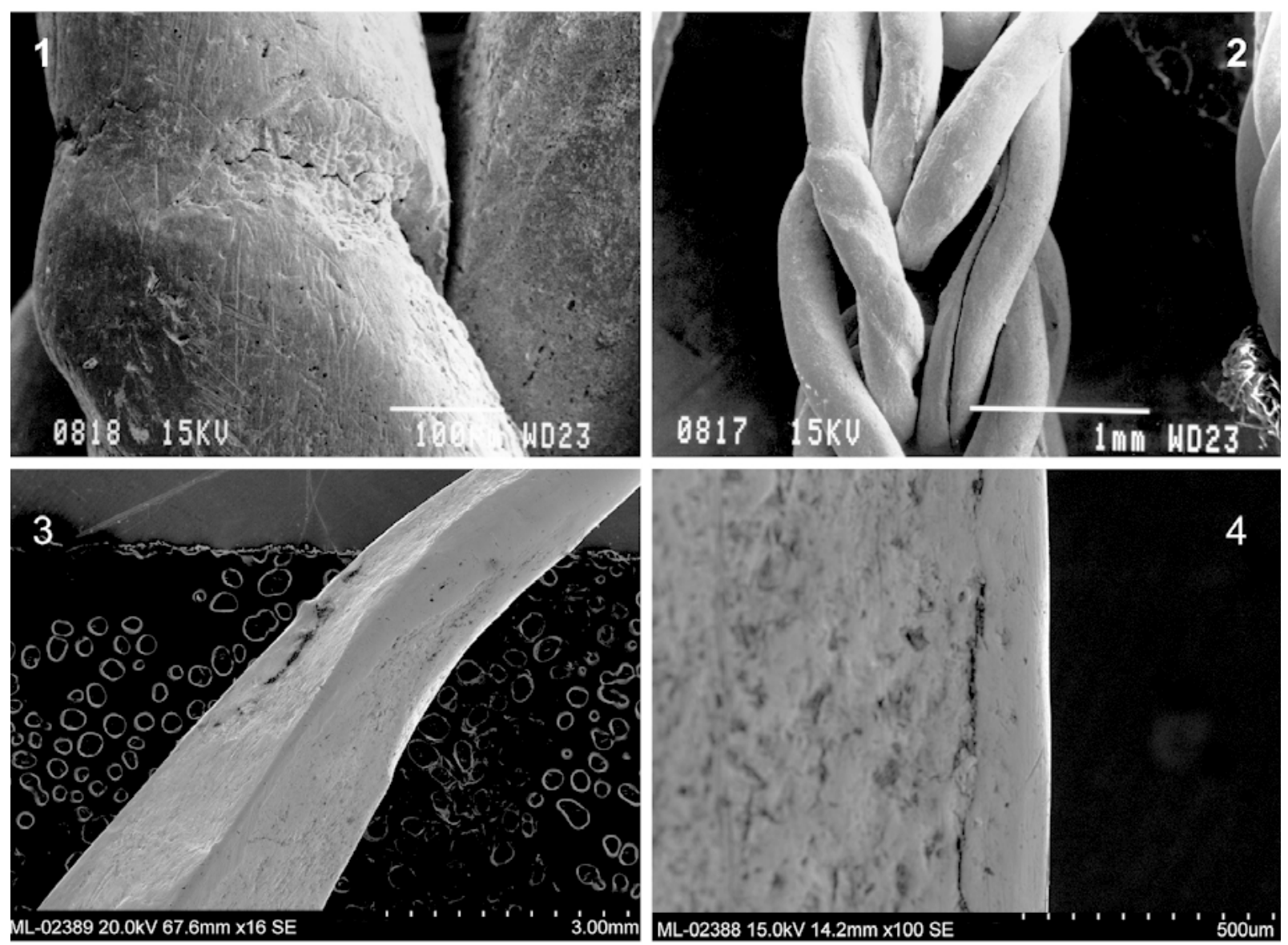

Fig. 3. Cadenilla de Chao Samartín: 1. soldadura en los extremos de un eslabón; 2. huellas helicoidales en los eslabones. Pendiente de Picu Castiellu: 3. huellas de trabajo en el aro; 4. detalle de las aristas del aro (imágenes de microscopía electrónica de barrido, SEM, de electrones secundarios): 1-2. Repertorio Au (Perea et al. 2010: 363); 3-4. Microlab (IH, CSIC).

siglos II-I a. n. e. (Camino 1995b: 247), pero no se han aportado datos detallados sobre su contexto de hallazgo. Ha sido vinculado tipológicamente con el "morfotipo I" establecido por B. Pérez Outeiriño (1982: 170-171) para las arracadas castreñas y con el "tipo F" propuesto por A. Perea (1991: 121) para los pendientes ibéricos. Se ha destacado la semejanza del tipo con pendientes de bronce procedentes de castros como Celada de Marlantes, Caravia, o el propio Picu Castiellu, contando también con paralelos en el área celtibérica (Camino 1995b: 247; Villa 2010: 116, 118119, 2019: 31, 33).

3. Se localizaron en el castro de Llagú, Latores, Oviedo, cuatro fragmentos de la misma pieza, conservados en el MAA, de los que estudiamos los dos de mayor tamaño (MAA 06670, Fig. 2: 3-4). Corresponden a un elemento de revestimiento tubular cuya superficie se decoró con puntos en resalte estampados (Fig. 2:
3-4). Uno presenta una zona sin decoración, ligeramente biselada (Fig. 2: 4, izquierda; Tab. 2: PA25139).

Incluimos con reservas en el inventario estos restos, recuperados en 1996 en un contexto arqueológico poco definido (Berrocal et al. 2002: 186-187, fig. 69-7)2 pero establecido en época romana a partir de su vinculación espacial con cerámicas comunes, por lo que no descartamos su datación en este período (Villa 2019: 31,33$)^{3}$. Los elementos laminares de revestimiento no son muy habituales en la orfebrería castreña. Contamos con algunos ejemplos en Asturias como

\footnotetext{
2 Véase también J. Ruibal Martínez y M. L. González Álvarez 1996: Memoria de la excavación de primera fase del yacimiento de Castiello de Llagú (Latores, Oviedo). Tomo III. Documento inédito depositado en el MAA.

Como sucede con dos anillos de plata del mismo castro (MAA 07026 y 07006), fechados respectivamente entre los siglos II-I a. n. e. y I d. n. e. (Berrocal et al. 2002: 186; Villa 2019: 33-35), que no han sido incorporados a este estudio.
} 


\begin{tabular}{|c|c|c|c|c|c|c|c|c|}
\hline $\begin{array}{l}\text { ID. } \\
\text { Análisis }\end{array}$ & Pieza & Procedencia & Invent. & Zona analizada & $\begin{array}{c}\mathrm{Au} \\
(\%)\end{array}$ & $\begin{array}{c}\text { Ag } \\
(\%)\end{array}$ & $\begin{array}{c}\mathrm{Cu} \\
(\%)\end{array}$ & Otros \\
\hline PA25135A & Cadena & $\begin{array}{l}\text { C. Chao } \\
\text { Samartín }\end{array}$ & 03671 & Eslabones & 70,1 & 27,3 & 1,36 & $\mathrm{~Pb}: 0,41$ \\
\hline PA25135B & Cadena & $\begin{array}{l}\text { C.Chao } \\
\text { Samartín }\end{array}$ & 03671 & Eslabones & 70,4 & 27,8 & 1,42 & $\mathrm{~Pb}: 0,43$ \\
\hline PA25136A & Torques & Asturias & 06643 & Aro & 1,6 & 73,3 & 24,7 & $\mathrm{~Pb}: 0,18$ \\
\hline PA25136B & Torques & Asturias & 06643 & Aro & 2,0 & 66,9 & 30,8 & $\mathrm{~Pb}: 0,27$ \\
\hline PA25137A & Arracada & $\begin{array}{l}\text { C. Picu } \\
\text { Castiellu }\end{array}$ & 08025 & Aro & 76,9 & 21,9 & 0,75 & Fe: 0,$25 ; \mathrm{Pb}: 0,22$ \\
\hline PA25137B & Arracada & $\begin{array}{l}\text { C. Picu } \\
\text { Castiellu }\end{array}$ & 08025 & Aro & 77,3 & 21,7 & 0,69 & Fe: 0,$18 ; \mathrm{Pb}: 0,1$ \\
\hline PA25138A & Lámina (f. A) & C. Llagú & 06670 & Reverso & 29,4 & 67,4 & 1,87 & $\begin{array}{l}\text { Fe: } 0,21 ; \mathrm{Ni}: 0,1 \\
\text { Pb: } 0,34\end{array}$ \\
\hline PA25138B & Lámina (f. A) & C. Llagú & 06670 & Anverso & 31,3 & 65,4 & 1,83 & $\begin{array}{l}\text { Fe: } 0,23 ; \text { Ni: } 0,16 \text {; } \\
\text { Pb: } 0,12\end{array}$ \\
\hline PA25139 & Lámina (f. B) & C. Llagú & 06670 & Anverso & 31,0 & 66,2 & 1,83 & $\begin{array}{l}\text { Fe: } 0,39 ; \mathrm{Ni}: 0,1 \\
\text { Pb: } 0,07\end{array}$ \\
\hline PA25140A & $\begin{array}{l}\text { Disco } \\
\text { decorado }\end{array}$ & Asturias & 03298 & Reverso cuenco & 38,9 & 40,8 & nd & $\begin{array}{l}\mathrm{Hg}: 18,9 ; \mathrm{Fe}: 0,21 ; \\
\text { Sn: } 0,45 ; \mathrm{Pb}, 0,13\end{array}$ \\
\hline PA25140B & $\begin{array}{l}\text { Disco } \\
\text { decorado }\end{array}$ & Asturias & 03298 & Anverso. Centro & 44,6 & 43,4 & 0,71 & $\begin{array}{l}\mathrm{Hg}: 10,54 ; \mathrm{Fe}: \\
0,33 \text {; Sn: } 0,28 ; \mathrm{Pb}: \\
0,11\end{array}$ \\
\hline PA25140C & $\begin{array}{l}\text { Disco } \\
\text { decorado }\end{array}$ & Asturias & 03298 & Anverso. Dec./Lám. & 20,9 & 71,8 & 1,44 & $\mathrm{Hg}: 5,48 ; \mathrm{Fe}: 0,43$ \\
\hline PA25140D & $\begin{array}{l}\text { Disco } \\
\text { decorado }\end{array}$ & Asturias & 03298 & Anverso. Decorado & 41,3 & 44,4 & 0,69 & $\mathrm{Hg}: 12,3$; Fe: 0,86 ; \\
\hline PA25141A & $\begin{array}{l}\text { Disco } \\
\text { decorado }\end{array}$ & Asturias & 03299 & Reverso Cuenco & 36,5 & 46,0 & $\mathrm{nd}$ & $\mathrm{Hg}=16,2 ; \mathrm{Fe}: 0,17$ \\
\hline PA25141B & $\begin{array}{l}\text { Disco } \\
\text { decorado }\end{array}$ & Asturias & 03299 & Anverso. Decorado & 50,3 & 34,6 & 0,46 & $\mathrm{Hg}=13,0 ; \mathrm{Fe}: 1,27$ \\
\hline PA25142A & $\begin{array}{l}\text { Torques (frag. } \\
\text { con terminal) }\end{array}$ & Asturias & 03540 & Terminal. Placa frontal & 52,4 & 42,6 & 1,55 & $\begin{array}{l}\mathrm{Hg}=0,71 ; \mathrm{Fe}: 2,01 ; \\
\text { Sn: } 0,29 ; \mathrm{Pb}: 0,1\end{array}$ \\
\hline PA25142B & $\begin{array}{l}\text { Torques (frag. } \\
\text { con terminal) }\end{array}$ & Asturias & 03540 & Aro. Extremo & 33,8 & 46,8 & 15,6 & $\begin{array}{l}\text { Fe: } 0,19 ; \mathrm{As}: 0,1 ; \\
\text { Sn: } 0,8 ; \mathrm{Pb}: 1,03\end{array}$ \\
\hline PA25142C & Torques s. p. 1 & Asturias & 03540 & Aro. Lateral & 46,1 & 41,8 & 10,7 & $\begin{array}{l}\text { Fe: } 0,95 ; \mathrm{Sn}: 0,4 ; \\
\mathrm{Pb}: 0,15\end{array}$ \\
\hline PA25142D & Torques s. p. 1 & Asturias & 03540 & Aro. Centro & 55,6 & 33,9 & 8,14 & $\begin{array}{l}\text { Fe: } 1,66 ; \mathrm{Sn}: 0,52 ; \\
\mathrm{Pb}: 0,1\end{array}$ \\
\hline PA25143A & Torques s. p. 1 & Asturias & 03300 & Aro. Centro & 29,7 & 50,0 & 16 & $\begin{array}{l}\mathrm{Hg}=2,6 ; \mathrm{Fe}: 1,67 \\
\mathrm{~Pb}: 0,11\end{array}$ \\
\hline PA25143B & Torques s. p. 2 & Asturias & 03300 & Aro. Lateral & 26,9 & 53,3 & 17 & $\begin{array}{l}\mathrm{Hg}=1,77 ; \mathrm{Fe}: 0,77 \\
\mathrm{~Pb}: 0,11\end{array}$ \\
\hline PA25143C & Torques s. p. 2 & Asturias & 03300 & $\begin{array}{l}\text { Resto terminal } \\
\text { (interior) }\end{array}$ & 2,41 & 23,1 & 70,1 & Fe: 1,$64 ; \mathrm{Pb}: 2,68$ \\
\hline
\end{tabular}

Tab. 2. Piezas del Museo Arqueológico de Asturias estudiadas. Resultados de los análisis por Fluorescencia de rayos-X (pXRF) expresados en $\%$ de peso. Los valores correspondientes a los elementos mayoritarios en la aleación $(\mathrm{Au} / \mathrm{Ag} / \mathrm{Cu})$ se presentan normalizados. El campo "Otros" incluye los valores del resto de elementos documentados, no normalizados. C Castro; nd no documentado o por debajo de límite de detección; s. p. sin procedencia; Dec./Lám. Decoración/Lámina; f, frag. Fragmento. 
un tubito de oro decorado con incisiones y un fragmento del castro de Campa Torres (Gijón) (Maya 1988: 142-143; Maya y Cuesta 2001: 134, 145-146; Villa 2019: 31) o algunos restos del castro de Chao Samartín (Villa 2004: 260-261, 2019: 32-33).

\subsection{Hallazgos antiguos}

Este grupo comprende tres torques fragmentados y dos discos decorados.

1. El aro de torques (MAA 06643, Fig. 4: 1) está elaborado con una aleación de plata y cobre. Presenta forma de "C" y sección circular, disminuyendo su grosor desde la zona central hacia los extremos, fracturados.
El ejemplar, que fue considerado como un torques de bronce (Maya 1988: 141) ha perdido su pátina original debido a su limpieza mediante tratamientos agresivos. Ello no impide que tenga un interés especial, dado el bajo número referenciado de torques castreños de plata respecto al alto número de torques de oro. $\mathrm{El}$ inventario de ejemplares de tipología castreña se limita a uno supuestamente procedente de Sobrado dos Monxes (A Coruña), conservado en el Museo Arqueológico Nacional (García-Vuelta 2007: 147-150), y a tres de procedencia incierta - un torques y dos brazaletes con forma de torques- ingresados en el Museo das Mariñas de Betanzos (Ladra et al. 2014). A los anteriores pueden sumarse varios fragmentos de torques del castro de Santa Tecla (Pontevedra), conservados en el museo de este
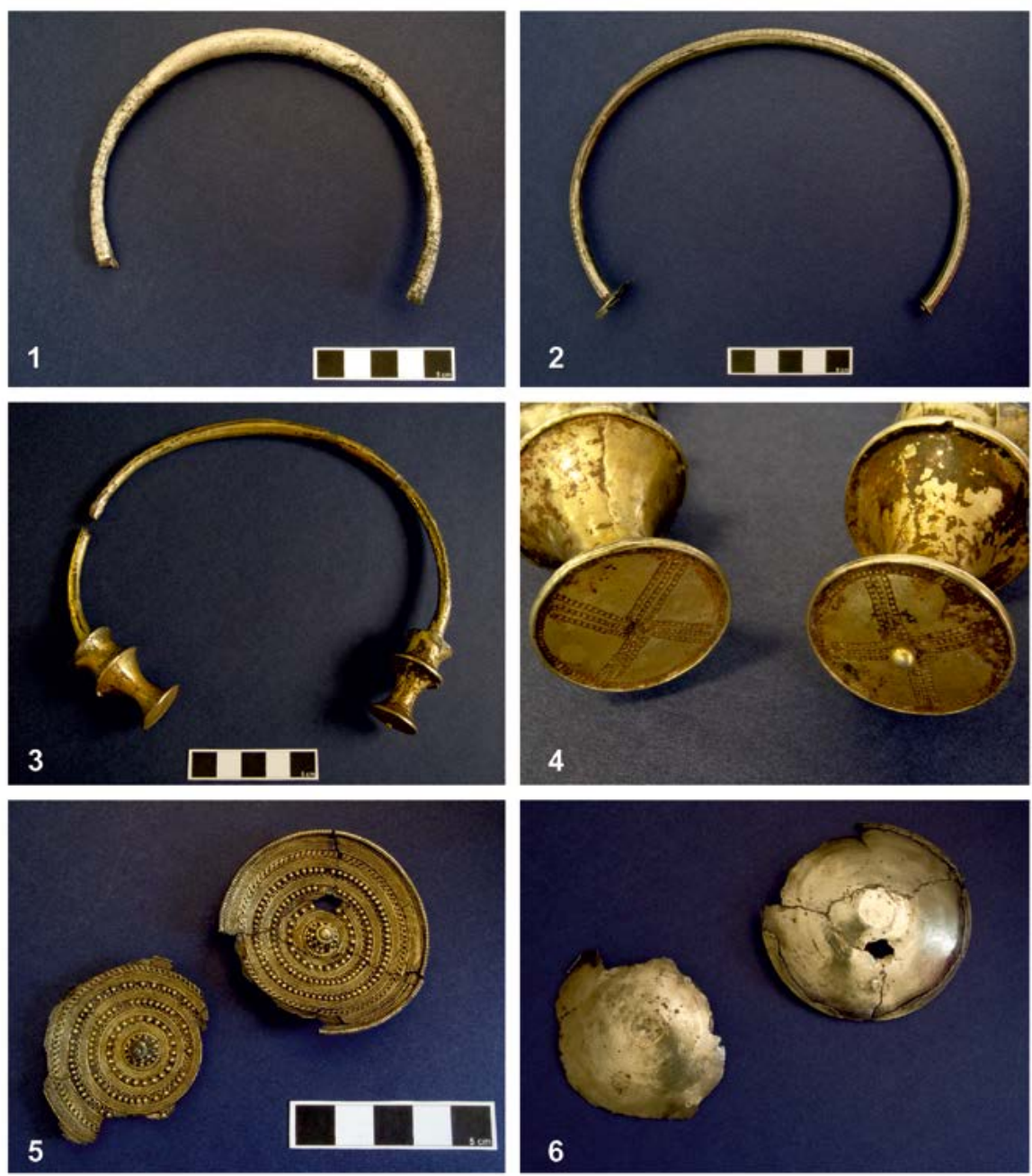

Fig. 4. Objetos del Museo Arqueológico de Asturias correspondientes a hallazgos antiguos sin procedencia: 1 . Torques n. ${ }^{\circ} 06643 ; 2$. Torques n..$^{\circ} 03300 ; 3$. Torques n. ${ }^{\circ} 03540 ; 4$. Detalle de los terminales del torques n. ${ }^{\circ} 03540 ; 5$. Discos n. ${ }^{\circ} 03298$ (izquierda) y 03299 (derecha), anverso; 6. Reverso de los discos. Fotos Óscar García Vuelta. 
yacimiento, cuyos aros -elaborados aparentemente con aleaciones de base cobre-, se recubrieron con plata (Carballo 1994: 30, 32).

2. El torques fragmentado y recompuesto (MAA 03540, Figs. 4: 3-4 y 5) tiene aro en forma de C, adelgazado desde el centro a los extremos, rematados con terminales angulares huecos decorados con perfil "en doble escocia". El aro se elaboró con una aleación argéntea sobre la que se aplicó un recubrimiento áureo (Hartmann 1982: 114-115; Escortell 1982: 83, fig. 405; Maya 1988: 141; Pingel 1992: 277-278; Villa 2010: 113, 115, 117).

El aro tiene sección mixta, poligonal en el tercio central y circular en los laterales e incluye tres acanaladuras ornamentales paralelas con superficie cóncava en su parte central exterior (Fig. 5: 1). Los terminales están constituidos por cuatro elementos básicos unidos por soldadura: dos cuerpos con perfil en escocia y dos placas circulares, que forman sus caras frontal y posterior (Fig. 5: 2). Los dos cuerpos centrales presentan huellas de corte reparadas (v. infra), disimulándose su unión por el ecuador mediante la soldadura de tiras acintadas, posteriormente pulidas. Las placas frontales de los terminales están decoradas con series de puntos en resalte estampados, que las bordean y forman un aspa rematada en el centro con un glóbulo soldado, actualmente perdido en un terminal (Fig. 5: 3). La placa posterior del terminal mejor conservado incluye una anilla moldurada que rodea al orificio por el que se inserta el aro (Fig. 5: 4).

El ejemplar ha sufrido graves alteraciones. Puede destacarse la recomposición moderna con aplicación de estaño de varios cortes en el aro y la restitución con el mismo procedimiento de uno de los terminales. Igualmente, estos elementos están muy afectados por rubefacción, cortes y posibles adiciones de material (v. infra).
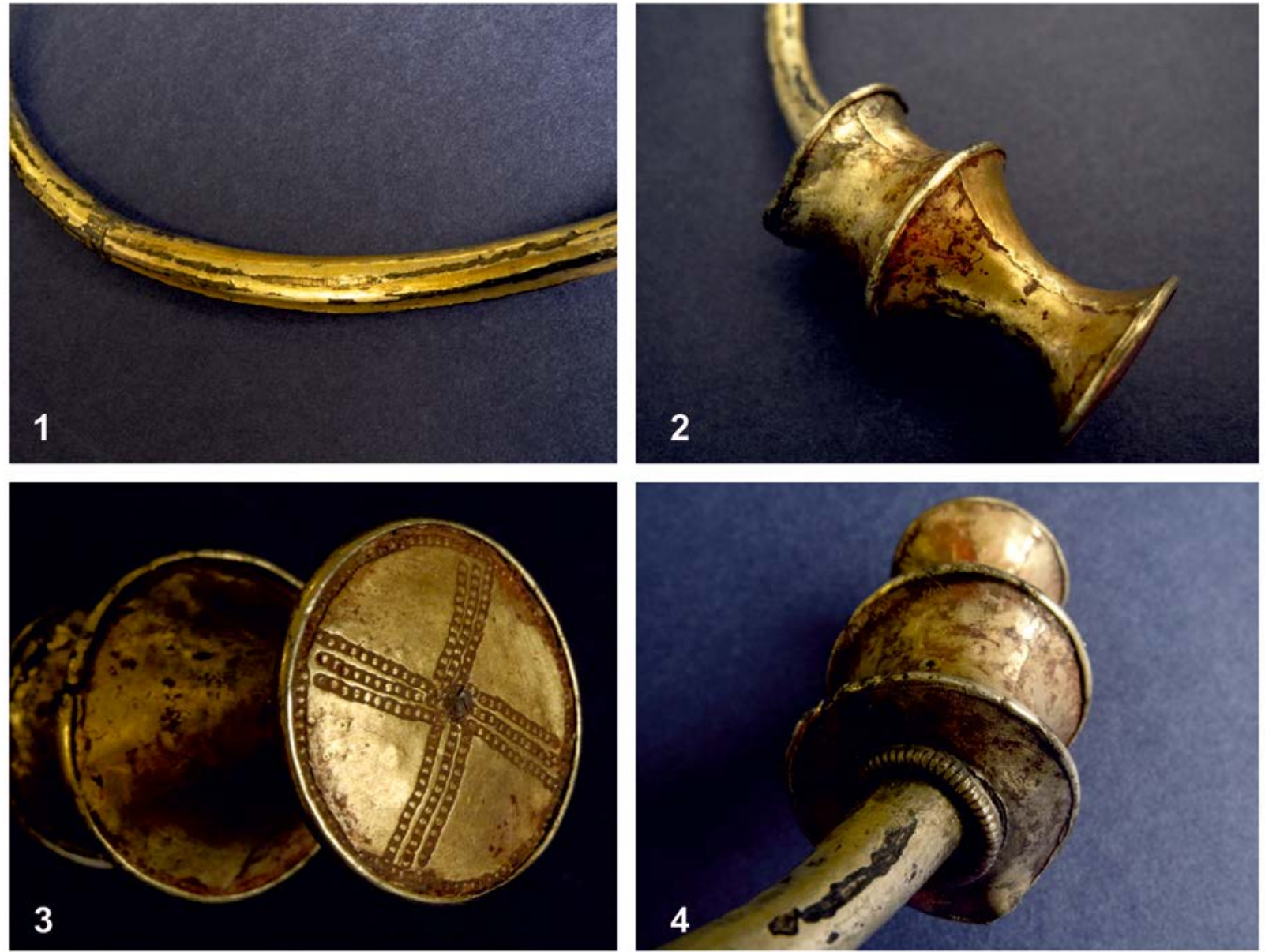

Fig. 5. Torques $n .^{\circ}$ 03540: 1. acanaladuras en la zona central exterior del aro, 2. terminal con huellas de cortes en los cuerpos centrales, 3 . decoración estampada en la placa frontal de este terminal, que ha perdido un glóbulo central soldado, 4. placa posterior del terminal con anilla moldurada. Fotos Óscar García Vuelta.

Trab. Prehist., 77, N. ${ }^{\circ}$ 1, enero-junio 2020, pp. 163-183, ISSN: 0082-5638

https://doi.org/10.3989/tp.2020.12252 
La capa de dorado del aro está muy deteriorada, apreciándose cortes y rozaduras en toda su superficie y una pequeña perforación circular hacia la parte central.

La pieza tiene paralelos entre los torques con terminales angulares del ámbito castreño, algunos de procedencia asturiana, como el $\mathrm{n}^{\circ} 03300$ de esta colección con el que podría guardar una relación de hallazgo, y otros que pertenecieron a la antigua colección Soto Cortés (López Cuevillas 1951 o García-Vuelta 2007, 2017, 2018).

3. El torques (MAA 03300, Figs. 4: 2 y 6) incorpora un aro decorado, en forma de C. Se elaboró con una aleación de base plata posteriormente dorada. Presenta sección mixta, poligonal en el tercio central y zonas próximas a los extremos y circular en la zona intermedia de los tramos laterales, disminuyendo su grosor desde el tercio central hacia los extremos. El torques incorporó terminales huecos con perfil en doble escocia, prácticamente perdidos (Escortell 1982: 84, fig. 406; Maya 1988: 141; Villa 2010: 115,117).

El aro, que fue caracterizado erróneamente como de bronce (Maya 1988: 141), alterna en su parte central exterior bandas de motivos circulares concéntricos con molduras de superficie cóncava, que incluyen series de líneas verticales cinceladas (Fig. 6: 1). En la zona central interior, no decorada, se observa una perforación circular, que probablemente corresponde a una comprobación de la naturaleza del metal (Fig. 6: 2). Las zonas exteriores próximas a los extremos están decoradas con series de círculos concéntricos estampados (Fig. 6: 3). Toda la superficie del ejemplar se encuentra notablemente alterada por cortes y rozaduras.

Los terminales de este torques presentaron una morfología similar a los del ejemplar n. $^{\circ} 03540$, con-
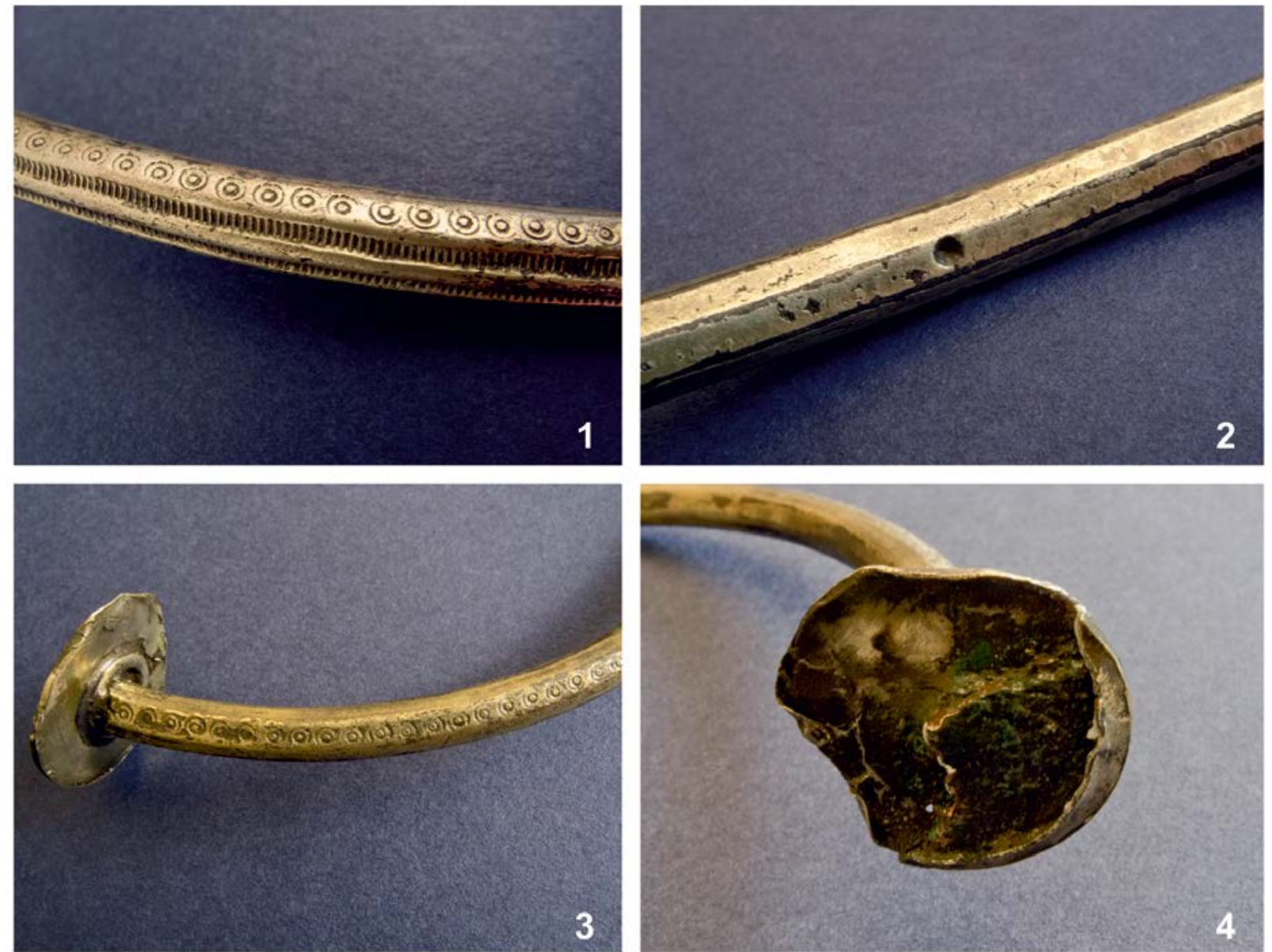

Fig. 6. Torques n. ${ }^{\circ}$ 03300: 1. acanaladuras y decoración de la parte central del aro, 2. perforación circular en la parte interior del aro, 3. decoración de los extremos del aro y placa posterior de un terminal, 4. vista frontal de la misma placa con restos del cuerpo posterior del terminal y material de base $\mathrm{Cu}$ en su interior. Fotos Óscar García Vuelta. 
servando únicamente parte de sus placas posteriores, que incorporan anillas de superficie lisa rodeando el orificio de entrada del aro. La placa en mejor estado conserva su diámetro original de ca. $2,1 \mathrm{~cm}$ y presenta restos de material soldante en su plano posterior, que no permiten confirmar si incluyó otros elementos ornamentales hoy perdidos (Fig. 6: 3). En la parte frontal, se aprecian restos de las paredes del cuerpo central posterior del terminal, así como una concreción metálica de composición $\mathrm{Cu}$ - Ag Ese material podría relacionarse con el proceso de elaboración del terminal (Fig. 6: 4), pero las manipulaciones que ha sufrido el ejemplar impiden verificarlo. Como se ha señalado, sus similitudes con el torques $n .{ }^{\circ} 03540$ podrían indicar su relación de hallazgo ( $v$. infra).

4. Las dos piezas discoidales incompletas decoradas (MAA 03298 y MAA 03299, Figs. 4: 5-6 y 7) se ase- mejan en su estructura y decoración, pero varían ligeramente en su tamaño. Integran cuerpos de base laminares en forma de cuenco, decorados por el anverso con bandas concéntricas de filigrana combinadas con glóbulos soldados, dispuestas en torno a un apéndice central troncocónico con el mismo tipo de ornamentación. El reverso de los discos es liso (Escortell 1982: 84, fig. 407; Maya 1988: 141; Villa 2010: 116-118).

Ambos ejemplares presentan graves deterioros y fueron recompuestos. Sus cuerpos de base se elaboraron con una aleación argéntea, dorándose posteriormente. Se fabricaron mediante embutido, apreciándose en la parte central de los reversos un rehundimiento de forma circular. El correspondiente al disco MAA 03299, mejor conservado, incorpora una lámina de refuerzo en la zona próxima al borde superior (Fig. 7: 1), recubierto con un hilo moldurado de ca. 1,8 $\mathrm{mm}$ de grosor (Fig. 7: 2).
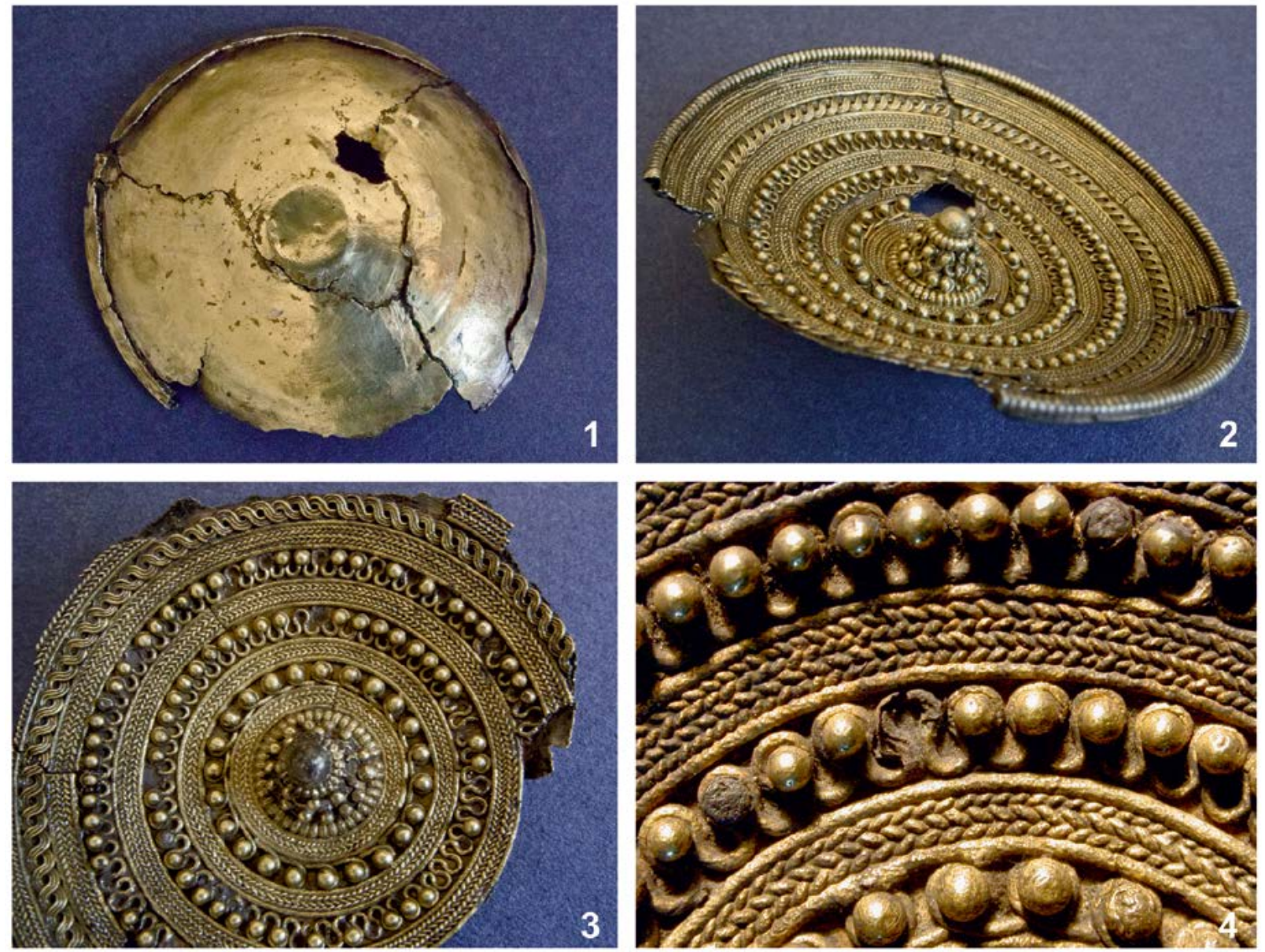

Fig. 7. Pareja de discos decorados n. ${ }^{\circ} 03288$ y 03299: 1. reverso del disco n. ${ }^{\circ} 03299$, 2. detalle de la decoración del anverso; 3. decoración del disco n. ${ }^{\circ}$ 03288, 4. detalle de las series ornamentales del mismo disco, con deterioros en el recubrimiento de algunos elementos. Fotos Óscar García Vuelta.

Trab. Prehist., 77, N. ${ }^{\circ}$ 1, enero-junio 2020, pp. 163-183, ISSN: 0082-5638

https://doi.org/10.3989/tp.2020.12252 
La decoración de los anversos incluye series de hilos lisos dispuestos "en espiga", de hilos lisos formando ondas sogueadas y meandros o bucles de hilos lisos rematados con glóbulos soldados, cuyos diámetros medios varían entre 1 y ca. $1,3 \mathrm{~mm}$. Cada banda está delimitada a su vez por hilos de superficie lisa.

Los apéndices centrales son huecos y de estructura laminar. Sus bases, soldadas a la superficie de los cuencos, están rodeadas por una anilla de hilo moldurado. En la parte central, incorporan dos bandas de filigrana con meandros de hilos lisos rematados por glóbulos con un diámetro inferior que los antes descritos. Sus extremos superiores se remataron con una anilla de hilo moldurado, sobre la que se dispone un glóbulo de ca. $3 \mathrm{~mm}$ (Fig. 7: 2-3).

A excepción de los moldurados, el resto de los hilos empleados en la ornamentación presenta sección circular y se elaboró a partir de la torsión de tiras laminares. Como veremos, el recubrimiento áureo afecta tanto a los cuerpos de base como a los elementos ornamentales -hilos y glóbulos- algunos de los cuales lo han perdido parcialmente (Fig. 7: 3-4).

Estos discos no cuentan por el momento con paralelos formales en la orfebrería castreña, aunque las composiciones ornamentales que integran sí están bien documentadas en este ámbito. Maya (1988: 141) los incluyó en su catálogo de orfebrería castreña asturiana, considerándolos parte de un adorno pectoral de tipo celtibérico. Sin descartar esa opción, apoyamos su interpretación como elementos de revestimiento, ya sea formando parte de un adorno de vestuario o de otra pieza de estructura más compleja.

\subsection{Los hallazgos antiguos: algunas notas documentales}

La falta de información sobre el contexto arqueológico de las piezas, así como sobre su "biografía reciente" sigue constituyendo un importante factor limitador de la investigación sobre la orfebrería castreña. Como es sabido, buena parte de los objetos conservados actualmente corresponde a hallazgos antiguos escasamente documentados, constituyendo en muchas ocasiones el estudio documental la única alternativa para aportar información sobre estas cuestiones (García-Vuelta 2017, 2018).

Sin embargo numerosos materiales carecen aún de este tipo revisiones, constituyendo las piezas del MAA un buen ejemplo de esa situación. El estudio sistemático de la documentación antigua conservada en el museo sigue pendiente y la falta de datos sobre estas piezas ha contribuido a la publicación de información poco contrastable. Así, se ha asumido la relación de hallazgo y la posible procedencia del concejo de Aller de los tor- ques MAA 03300 y MAA 03540 (Villa 2010: 116-117). Esta propuesta se basa en un comentario aportado por el erudito gijonés J. Somoza sobre torques que a principios del siglo XX pertenecían al coleccionista asturiano Soto Cortés ${ }^{4}$. La procedencia de Aller de los ejemplares en poder de Soto Cortés también fue aceptada por algún investigador (Maya 1988: 141), pero hay que aclarar que el comentario de Somoza estaba inserto en su crítica a un estudio previo de E. Tuñón (1858). Este autor se refirió a varios hallazgos arqueológicos producidos en este concejo, incluyendo uno que pudo estar integrado por piezas de oro ${ }^{5}$. Sin embargo, esta información no puede confirmarse. Hay que precisar también que Somoza no aludió a la procedencia de los torques de Soto, que se han relacionado con un hallazgo producido en Laviana a finales de 1901 (García-Vuelta 2007: 114, 2018: 1406-1409). Habrá que esperar que nuevos datos confirmen o descartan estas informaciones, pues tampoco otras noticias sobre posibles hallazgos de torques en Aller (García-Vuelta et al. 2016) pueden vincularse directamente con las piezas del MAA.

Hasta el momento, no se ha presentado ningún dato sobre las circunstancias de ingreso del torques de plata MAA 06643 o la pareja de discos MAA 03298 y MAA 03299. Sin esa información no podemos aventurar posibles relaciones de hallazgo entre estas piezas y los torques MAA 03300 y MAA 03540. Cabe conectar sin embargo el ingreso de los tres torques con la actividad de los miembros de la "Comisión Provincial de Monumentos de Asturias" (Adán 1999), quizá a través de donaciones o de compras no documentadas (Maya 1988: 141). Una fotografía hasta ahora inédita (Fig. 8) los sitúa ya en la institución en 1903. El documento fue encargado por el ya mencionado Soto Cortés -vocal de la Comisión desde 1887 hasta 1915 (Garriga y Palau 1915: 6)-, que lo conservó en su archivo particular ${ }^{6}$. En la imagen el estado de los torques MAA 03300 y MAA 03540, anotados como 1 y 2, difiere del actual. El aro de este último ya está reconstruido, pero parece que sin un fragmento que incorpora actualmente en uno de sus extremos (Fig. 4:

\footnotetext{
4 "Los objetos encontrados en Aller, debían ser muy apreciables, como lo son los de un reciente hallazgo (1901), del que formaban parte varios torques de oro macizo, algunos de los cuales posee hoy el aficionado Sr. Soto Cortés" (Somoza 1971 [1908]: 36). Sobre la colección Soto Cortés y su figura (1833-1915) véanse p. ej. Diego Somoano 196061; Rodríguez Álvarez 2002 o García-Vuelta 2017, 2018).

5 "Según me aseguraron, también en Aller hubo un hallazgo de un juego de instrumentos religiosos de sacrificios paganos que fueron traídos a Oviedo para ser enajenados, pero no pude averiguar su paradero a pesar de las diligencias que practiqué para el efecto" (Tuñón 1858: 10).

${ }^{6}$ En el reverso Soto Cortés anota: "Museo Arqueológico-Oviedo1 y 2. Torques de oro de mala ley. 3. Restos de otro de plomo. Fotografía del Sr. Mariano Balbín, 1903. Oviedo". Agradecemos a los Sres. Quirós, propietarios del palacio de los Soto (Labra, Cangas de Onís), las facilidades prestadas para la localización de este y otros documentos (García-Vuelta 2017, 2018).
} 


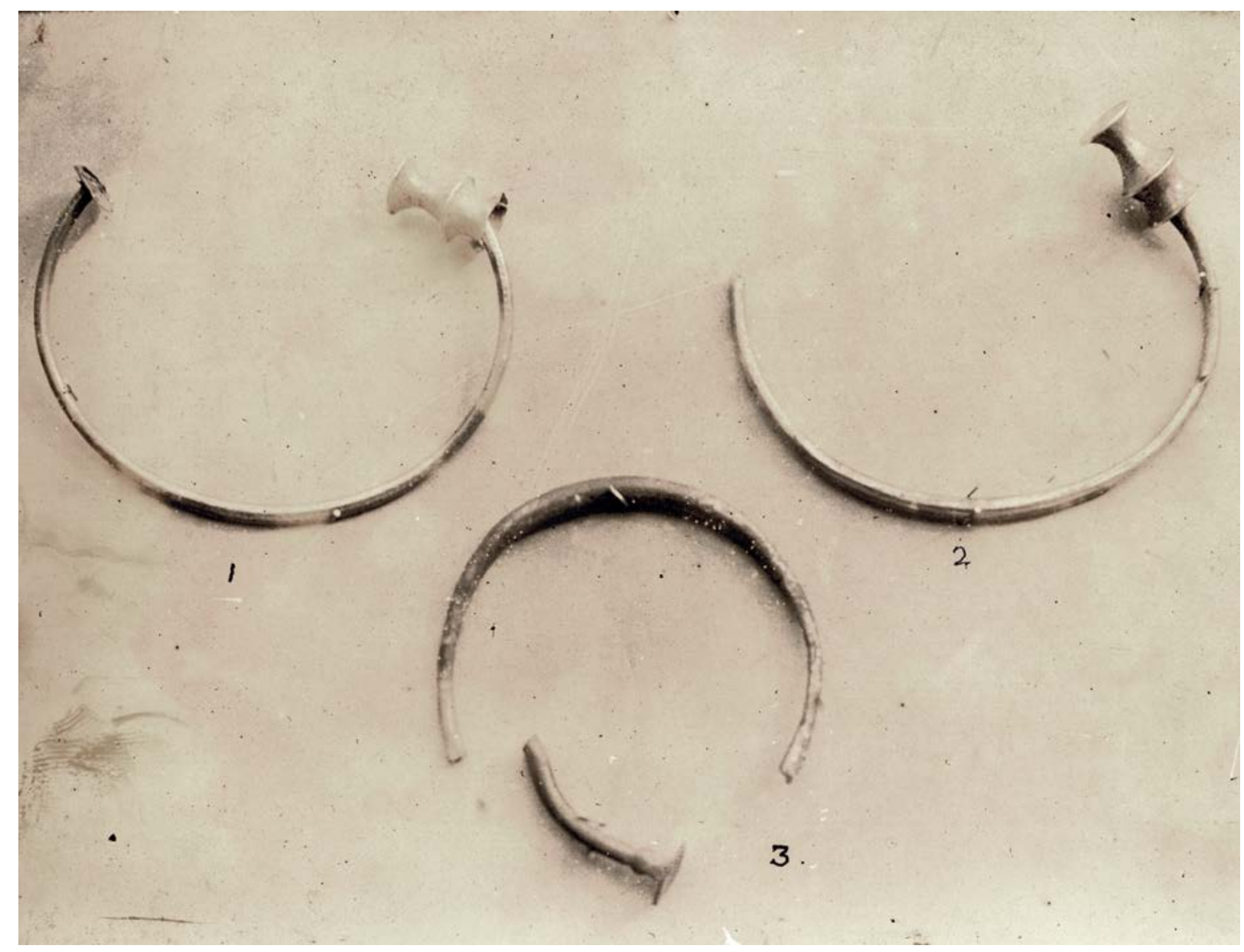

Fig. 8. Fotografía inédita fechada en 1903 en la que aparecen los torques estudiados del Museo Arqueológico de Asturias. Archivo particular del coleccionista Sebastián de Soto Cortés.

3). Uno de los terminales hoy añadido a esta pieza figura desgajado y dispuesto junto al ejemplar MAA 03300 , careciendo de su placa posterior, después recompuesta (v. infra).

El torques MAA 06643, anotado con el n. ${ }^{\circ} 3$, parece conservar su pátina original. Se dispone junto a un objeto incompleto, probablemente el interpretado como un freno de caballo de bronce (MAA 03594) del castro de La Escrita (Doirás, Boal) (Escortell 1982: 65, fig. 21; Maya 1988: 85, 89). Soto Cortés volvió a aludir por esos años a los torques del MAA en su correspondencia con el investigador José Ramón Mélida (García-Vuelta 2007: 113-114, 2017), mencionando su origen asturiano, pero sin aportar datos sobre su procedencia o circunstancias de hallazgo ${ }^{7}$.

\footnotetext{
7 "Encuéntranse en Asturias alguna que otra vez Torques, en el Museo Arqueológico de Oviedo hay dos de oro... de baja ley, y restos
}

\section{ESTUDIO ARQUEOMÉTRICO}

\subsection{Aportaciones previas}

Los primeros análisis de composición sobre las piezas del MAA se realizaron desde el proyecto alemán Studien zu den Anfängen der Metallurgie (SAM). Corresponden a uno de los discos laminares de cronología campaniforme (Hartmann 1982: 96-97, Au 2890; Pingel 1992: 263) y al torques MAA 03540 (Hartmann 1982: 114-115, Au 2891; Pingel 1992: 277-278). Los resultados se obtuvieron sobre muestras de las piezas, recurriéndose al análisis por vía húmeda o mediante gravedad específica para la cuantificación de la plata en porcentajes superiores a ca. $1 \%$ y también a la

de otro de plomo". Borrador de carta dirigida a J. R. Mélida de abril de 1906 (García-Vuelta 2017: 177). 
espectroscopia óptica de emisión para la de valores inferiores de ese elemento y para la del estaño, el cobre y otros elementos traza.

Las aportaciones posteriores han empleado procedimientos no destructivos. En 1985 se caracterizó por fluorescencia de rayos-X (XRF) el anillo de tiras de Mata l'Casare I (MAA 03256), desde el Proyecto "Arqueometalurgia de la Península Ibérica" (API) (Blas Cortina 1994: 11, 2013: 108) ${ }^{8}$. En 2010 vieron la luz los resultados de los estudios topográficos y de composición realizados en el Proyecto Au (IH, CSIC) mediante el uso combinado de microscopía electrónica de barrido y microanálisis por energía dispersiva de rayos- $\mathrm{X}$ (SEM-EDX). Este trabajo aportó nuevos datos sobre los objetos de oro de Chao Samartín (Perea et al. 2010: 358-368.), incluyendo los correspondientes a la cadenilla n. ${ }^{\circ} 03671$ (Perea et al. 2010: 362-363) ${ }^{9}$. La contribución más reciente ha afectado a la pareja de discos decorados de cronología campaniforme (MAA 03257 y MAA 03258), incluyendo su revisión topográfica y su análisis por XRF y microsonda electrónica de barrido -EPMA- (Fernández Moreno et al. 2018: 73-77) ${ }^{10}$.

\subsection{Resultados}

Los análisis pXRF de la cadenilla de Chao Samartín (Tab. 2: PA25135 A-B) indican que se elaboró con una aleación de base $\mathrm{Au}$ que tiene una tasa de plata relativamente alta (ca. $28 \%$ ) y poca presencia de cobre $(<1,5$ $\%$ ). El plomo (ca. 0,5\%) puede relacionarse con los procesos de copelación para obtener la plata.

La pieza no fue revisada por SEM-EDX al disponerse de un estudio anterior (Perea et al. 2010: 362363). Destacan las diferencias entre los resultados obtenidos. Los análisis SEM-EDX previos (Tab. 3) distinguieron las composiciones de los hilos y las zonas de soldadura, apuntando al uso de un oro de elevada pureza. En los hilos la plata no superó valores del $4 \%$ y no se detectó cobre. En las soldaduras el valor de plata fue ligeramente superior (Perea et al. 2010: 358) con una tasa máxima del $6 \%$ y baja presencia de cobre $(<0,5 \%)$ (Perea et al. 2010: 362).

Estas variaciones pueden atribuirse a un proceso de enriquecimiento superficial del oro de apenas unas micras de espesor. La diferente capacidad de penetra-

\footnotetext{
8 Análisis obtenido en el Instituto de Patrimonio Histórico Español por el Dr. S. Rovira, utilizando un espectrómetro KEVEX, mod. 7000 (ref. análisis: AA1256). Sobre el Proyecto API véase Rovira y Montero Ruiz 2018.

${ }^{9}$ Estudio en colaboración con el Centro Nacional de Investigaciones Metalúrgicas (CSIC) y dirigido por A. Perea (IH, CSIC) (Perea et al. 2010: 13-14).

${ }_{10}$ Realizados en los Servicios Científico-Técnicos de la Universidad de Oviedo (Fernández-Moreno et al. 2018: 73)
}

\begin{tabular}{|c|l|c|c|c|}
\hline Id. Análisis & \multicolumn{1}{|c|}{ Estructura } & $\begin{array}{c}\mathbf{A u} \\
\mathbf{\%}\end{array}$ & $\begin{array}{c}\mathbf{A g} \\
\mathbf{\%}\end{array}$ & $\begin{array}{c}\mathbf{C u} \\
\mathbf{\%}\end{array}$ \\
\hline AUCHA02201 & Eslabón-Hilo & 96,6 & 3,44 & -- \\
\hline AUCHA02202 & Eslabón-Hilo & 97,1 & 2,93 & -- \\
\hline AUCHA02203 & Eslabón-Hilo & 99,2 & 0,83 & -- \\
\hline & Promedio & 97,60 & 2,4 & -- \\
\hline AUCHA02204 & Eslabón-Soldadura & 93,2 & 6,65 & 0,18 \\
\hline AUCHA02205 & Eslabón-Soldadura & 96,1 & 3,63 & 0,24 \\
\hline AUCHA02206 & Eslabón-Soldadura & 96,8 & 3,15 & -- \\
\hline & Promedio & 95,39 & 4,48 & 0,14 \\
\hline
\end{tabular}

Tab. 3. Cadenilla de Chao Samartín. Resultados de los análisis previos mediante microscopía electrónica de barrido por energía dispersiva de rayos-X (SEM-EDX). Valores normalizados y expresados en $\%$ de peso. Datos según Perea et al. 2010: 362.

ción en la superficie de las técnicas analíticas empleadas, sensiblemente menor en EDX que en XRF (p. ej. Troalen et al. 2014: 220 -221), hacen a la primera más sensible a este tipo de fenómenos. Como consecuencia, estos resultados no son suficientemente representativos de la composición original del metal (Monge et al. 2017; Blet-Lemarquand et al. 2018). Esto permite reconsiderar los datos de composición de esta cadenilla, e integrarlos en un rango más acorde con los documentados en otras manufacturas castreñas, caracterizadas por una mayor presencia de plata (v. infra).

La comparación de resultados entre $\mathrm{pXRF}$ y SEMEDX pudo realizarse también con la arracada de Picu Castiellu de Moriyón. Según los primeros (Tab. 2: PA25137 A-B) se elaboró con una aleación de base $\mathrm{Au}$, que tiene una proporción de plata de ca. $22 \%$, valores bajos de cobre $(<1 \%)$ y trazas de plomo. De nuevo los resultados promediados de los análisis SEMEDX (Tab. 4) mostraron tasas de plata sensiblemente inferiores (ca. $10 \%$ ), atribuibles al enriquecimiento del contenido de oro en superficie, coincidiendo con los valores de cobre registrados.

Las dataciones publicadas para la fase de ocupación del castro de la que procede el ejemplar corresponden en buena medida a momentos previos a la conquista romana, con un contexto arqueológico característico de la Edad del Hierro que refrenda la atribución cultural y cronológica propuesta por su excavador (Camino 1995a: 119 y 125; Armada y García-Vuelta 2015: 373). En ese sentido, cabe destacar que las composiciones documentadas por pXRF para el pendiente coinciden con las estimadas para los oros aluviales empleados en el noroeste en la etapa prerromana con valores de hasta ca. $25 \%$ de plata y ca. $1 \%$ de cobre (Montero Ruiz y Rovira 1991: 10). Esos resultados difieren de los valores obtenidos con la misma técnica 


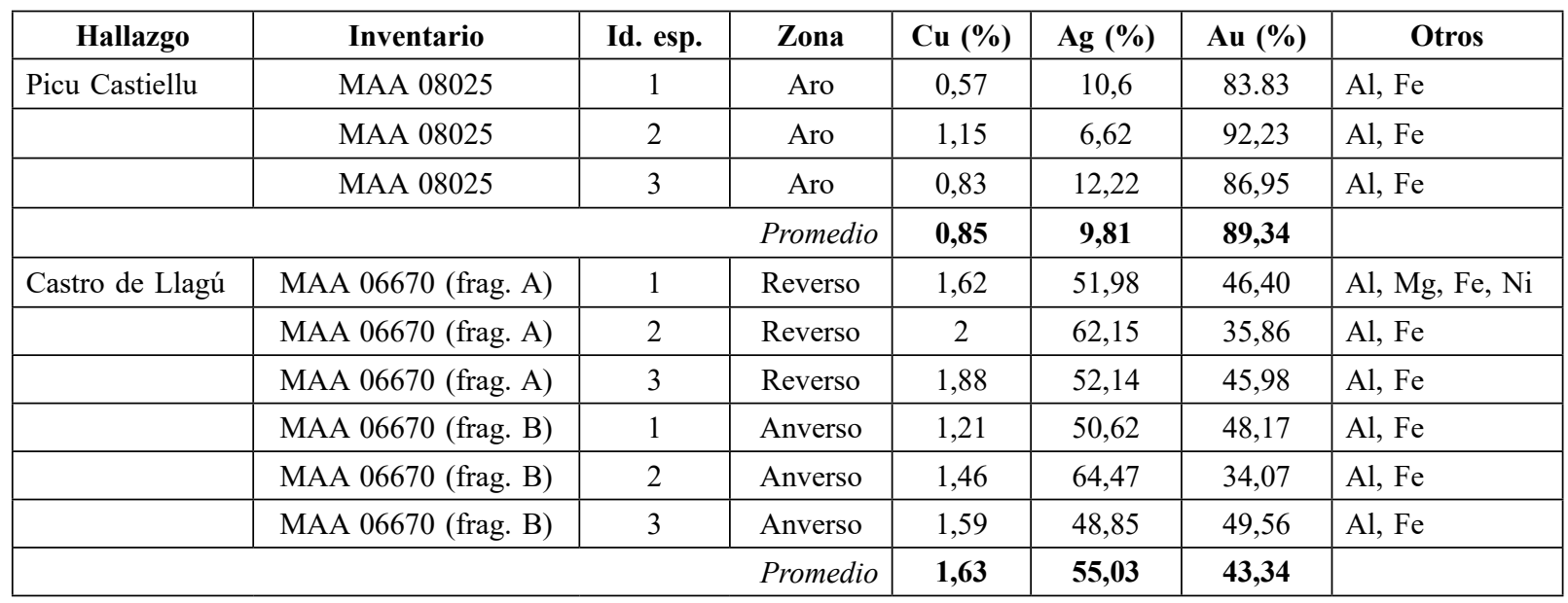

Tab. 4. Resultados de los espectros mediante microscopía electrónica de barrido por energía dispersiva de rayos-X (SEM-EDX) correspondientes al pendiente de Picu Castiellu (superior) y a los restos laminares del castro de Llagú (inferior), considerando los elementos mayoritarios de la aleación. Valores normalizados y expresados en \% de peso. Id. esp. Identificador de espectro.

sobre otras piezas castreñas en las que se documentan aleaciones ternarias $\mathrm{Au}-\mathrm{Ag}-\mathrm{Cu}$ (García-Vuelta y Montero 2007: 102; Guerra y Tissot 2015: 9; MartinónTorres y Ladra 2018: 50-53), probablemente correspondientes a momentos posteriores.

Los restos laminares de Llagú se han descrito como piezas de oro (Berrocal et al. 2002: 186). Sin embargo, los análisis pXRF (Tab. 2: PA25138 A-B; PA25139) confirman que el elemento predominante en su composición es la plata (ca. $67 \%$ ) con un alto contenido de oro (ca. $30 \%)$, una baja presencia de cobre $(<2 \%)$ y trazas de plomo. En este caso, los espectros SEMEDX (Tab. 4) muestran valores promediados algo más próximos a los recogidos con $\mathrm{pXRF}$, pero pueden apreciarse diferencias de hasta ca. $10 \%$. Aunque algunos indican proporciones próximas de oro y plata, otros evidencian tasas de plata más variables, que superan entre un $5 \%$ y un $30 \%$ a los del oro. Los valores de cobre se mantienen estables, no sobrepasando el $2 \%$. La posibilidad de que esas variaciones se debieran a un dorado superficial irregularmente conservado no pudo verificarse por la abundante presencia de material de restauración.

Los análisis del torques MAA 06643 (Tab. 2: PA25136 A-B) indican que se elaboró con una aleación de plata con alto contenido de cobre ( $>25 \%$ ). Probablemente la corrosión de este elemento se hizo patente en el aspecto de la pátina original del ejemplar, hoy perdida, contribuyendo a que fuese interpretado como un objeto de bronce (Maya 1988: 141). No se documentan evidencias de dorado, pudiendo asociarse los valores de oro recogidos (ca. 1-2 \%) a la plata utilizada. Se han identificado pequeñas cantidades de plomo, también asociadas a la plata.
Aunque esta pieza no pudo ser revisada en el SEM, su estudio topográfico aporta algunas cuestiones a valorar. Las fracturas impiden verificar si incorporó terminales en los extremos, pero su morfología coincide con la de otros torques castreños que sí los incluyeron (Armbruster y Perea 2000; Perea 2003). La parte central del aro, mejor conservada, está bien diferenciada de los tramos laterales, más delgados y de acabado irregular (Fig. 9: 1). En estas zonas laterales se identifican series de marcas longitudinales paralelas (Fig. 9: 2) de interpretación dudosa. Podrían relacionarse con la presencia original de tramos de "alambres enrollados", elementos de recubrimiento característicos de algunos grupos de torques castreños (López Cuevillas 1951; Monteagudo 1952). La alteración del ejemplar impide aportar conclusiones definitivas, pero la práctica de recubrir con ese tipo de elementos la superficie de aros no áureos de torques está documentada en la orfebrería castreña. Puede observarse por ejemplo en ejemplares que incluyen aros elaborados con aleaciones de base cobre, como uno de tipo "Ártabro" del castro lucense de Viladonga (Ladra y Martinón-Torres 2009: 33-34), o tres piezas con terminales vasiformes del castro de Lanhoso (Braga, Portugal) (Silva 2007 [1986]: 353-354, lám. CXI, 1-3).

Tanto el estudio topográfico como los análisis pXRF del torques MAA 03300 (Tab. 2: PA25143 A-C), confirman que su aro se elaboró con una aleación de plata-cobre, posteriormente dorada. El tamaño del área mínima de muestreo del espectrómetro utilizado no ha permitido diferenciar con exactitud la composición del alma y de su recubrimiento áureo. Los resultados correspondientes al aro muestran valores máximos de plata de ca. $54 \%$, pero este elemento aparece infra- 

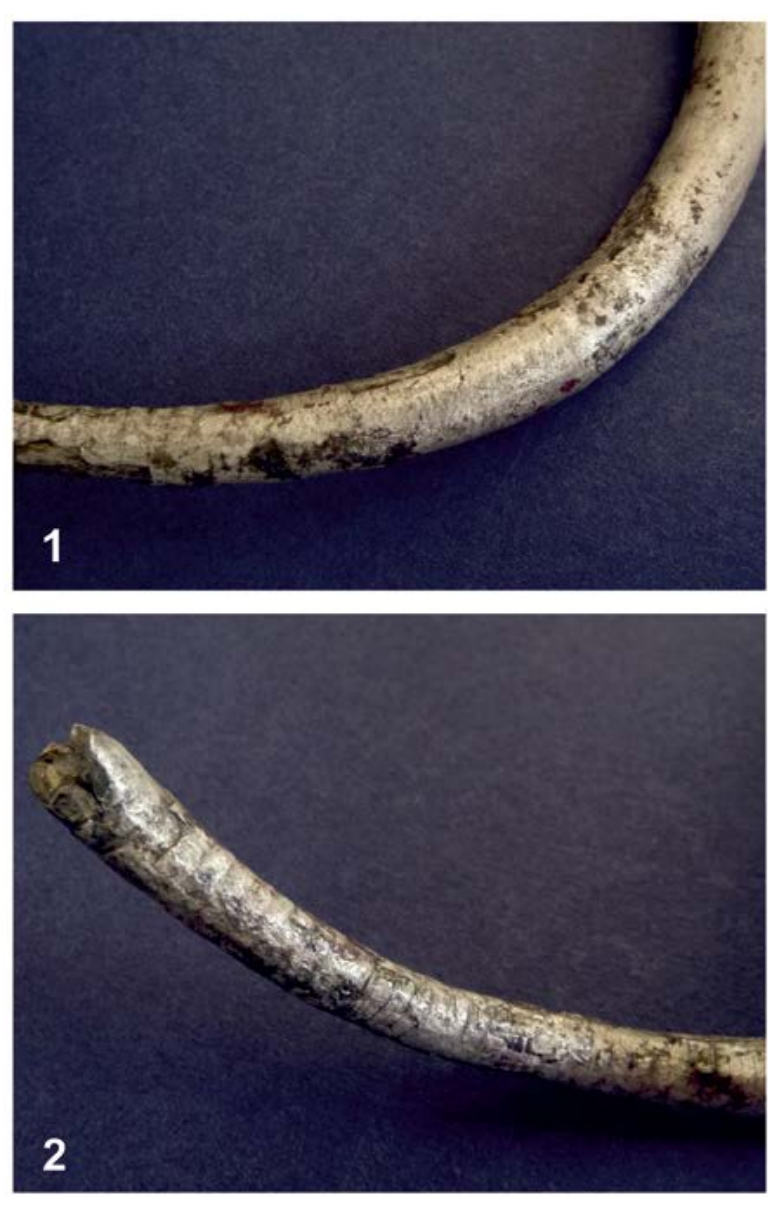

Fig. 9. Torques n. ${ }^{\circ}$ 06643: 1. aspecto de la zona central del aro, 2. detalle de uno de los tramos laterales con series de marcas paralelas. Fotos Óscar García Vuelta.

valorado por la presencia de restos de dorado. Sucede lo contrario en la estimación del oro (ca. $29 \%$ ), pues los análisis afectan al alma interior de la pieza. Como en ambos casos el cobre ofrece valores altos $(>15 \%)$, parece adecuado pensar que el alma presenta un porcentaje significativo de este metal.

Un dato muy relevante es la documentación de mercurio en el recubrimiento áureo del aro, aunque en una proporción que podemos considerar baja $(<3 \%)$. $\mathrm{Su}$ presencia puede relacionarse con la aplicación de un dorado por amalgama, procedimiento no identificado hasta fecha reciente en las producciones orfebres castreñas (v. infra).

El muestreo XRF de los restos metálicos localizados en la cara interior de la placa de terminal mejor conservada (Fig. 6: 4; Tab. 2: PA25143 C) muestra elevados valores de cobre (ca. $70 \%$ ) y plata (ca. 23 $\%$ ) con baja presencia de oro (ca. $2 \%$ ). Podrían co- rresponder tanto a una degradación del material soldante empleado en esta zona, como a manipulaciones posteriores al hallazgo. La parte posterior de las placas de los terminales no pudo ser analizada en el SEM debido a la geometría del ejemplar, que por su tamaño tampoco pudo ser revisado con esta herramienta.

El torques MAA 03540 presenta semejanzas formales y tecnológicas con la pieza anterior, pero también algunas diferencias. Según los análisis pXRF (Tab. 2: PA 25142 B-D) su aro se elaboró con una aleación de plata y cobre, dorándose después. En este caso, no ha podido determinarse con claridad una presencia de mercurio que confirmara el uso de un dorado por amalgama. Los nuevos datos de composición obtenidos se aproximan al análisis publicado desde el proyecto SAM, que documenta una tasa de cobre más alta, pero no localizan la zona muestreada ${ }^{11}$. Los resultados de ambos estudios no son directamente comparables, pero confirman que el alma interior se elaboró con una aleación de plata-cobre.

Como sucedió en la pieza MAA 03300, el área mínima de muestreo no permitió diferenciar las composiciones del material de base del aro y su recubrimiento. El valor máximo de plata, obtenido en el fragmento desprendido, se sitúa en ca. $47 \%$, con una tasa de cobre de ca. $16 \%$ (Tab. 2: PA25142 B). El valor mínimo (34\% Ag) se detecta en la parte central del aro con valores de cobre de ca. $8 \%$ (Tab. 2: PA25142 D). No se documentan evidencias de dorado en el análisis correspondiente a la placa frontal de uno de los terminales, que aportó un valor de c. $52 \%$ de oro, ca. $43 \%$ de plata y 1,5\% de cobre (Tab. 2: PA25142 A).

La presencia de material de restauración impidió un adecuado estudio topográfico y analítico de esta pieza con SEM-EDX. Solo algunas zonas del terminal desprendido pudieron ser analizadas, sin que por razones de geometría fuese posible la inspección del fragmento de aro asociado al terminal (Fig. 10: 1). No se confirmó la aplicación de dorado y los resultados -que comentamos a nivel cualitativo- registraron valores de plata superiores a los obtenidos mediante pXRF en el aro, superando un $50 \%$ en la composición de los cuerpos centrales del terminal y ca. $40 \%$ en su anilla posterior.

Las alteraciones sufridas por la pieza no han impedido documentar evidencias antiguas de trabajo, como las perforaciones con rebabas suavizadas que los terminales incluyen en sus cuerpos centrales posteriores (Fig. 10: 2). Pueden interpretarse como orificios de evacuación de los gases producidos durante la soldadura de los elementos constituyentes del ter-

${ }^{11}$ ca. $35 \%$ Au; ca. $40 \%$ Ag; ca. $25 \%$ Cu (Hartmann 1982: 114115, Au 2891; Pingel 1992: 277-278). 

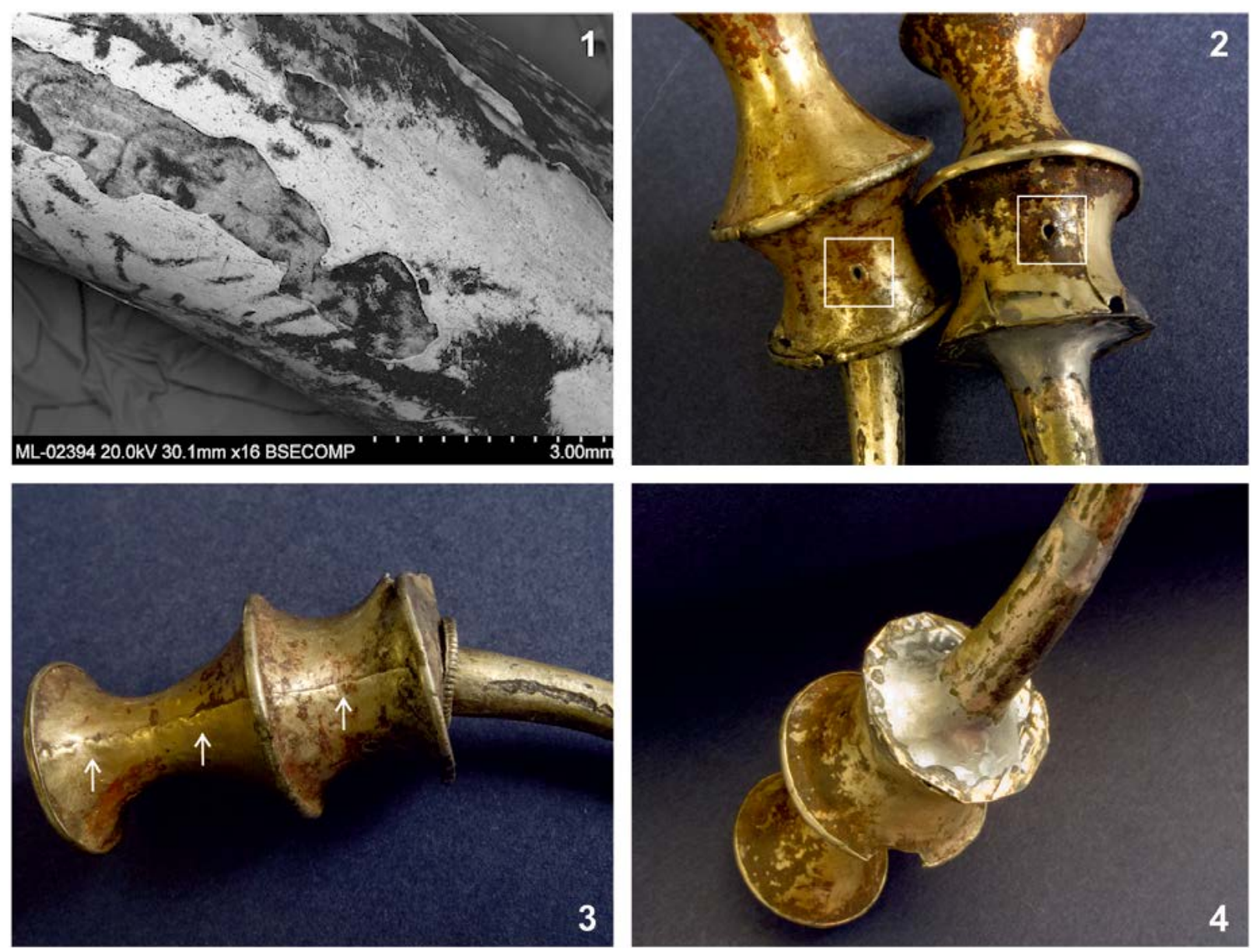

Fig. 10: Torques n. ${ }^{\circ}$ 03540: 1. deterioros en la capa de dorado (en color claro) en un fragmento del aro (imagen de microscopía electrónica de barrido, SEM, de electrones retrodispersados); 2. detalle de orificios de evacuación de gases en los cuerpos de los terminales, 2 . cortes longitudinales recubiertos con oro y fracturas en el terminal mejor conservado, 3. detalle de la reconstrucción de un terminal, fijado con estaño. Fotos Microlab (IH, CSIC), Óscar García Vuelta.

minal, destinados a evitar posibles deformaciones en el metal durante el proceso térmico. Esa solución técnica se había identificado ya en torques castreños con terminales angulares huecos, entre ellos los de procedencia asturiana conservados en el Instituto Valencia de Don Juan o el Museo Arqueológico Nacional (Armbruster y Perea 2000: 104; García-Vuelta 2007: 90, 97, 107).

Otras evidencias ofrecen una interpretación más dudosa. Por ejemplo, los cuerpos centrales de los terminales presentan huellas longitudinales de corte recubiertas con oro (Fig. 10: 3), que no afectan a las zonas de contacto entre los elementos del terminal, donde sí se documentan otras fracturas (Fig. 10: 4). Una primera hipótesis los relacionaría con un proceso de elaboración de los cuerpos consistente en la deformación plástica de chapas de oro, cuyos bordes se soldarían después. Sin embargo, este procedimiento no ha sido documentado en los ya numerosos torques castreños con terminales angulares estudiados (Armbruster y Perea 2000). Una segunda interpretación, más probable, apunta a una reparación tras el hallazgo. Esto implicaría que los elementos que recubren las uniones de las diferentes partes de los terminales $-\mathrm{O}$ al menos parte de ellos- se habrían añadido después. Lo mismo sucede con la placa posterior del terminal reconstituido (Fig. 10: 4), que no figura en la documentación de 1903 (v. supra).

Los análisis pXRF de los discos n. ${ }^{\circ} 03298$ y 03299 (Tab. 2: PA25140 A-D; PA25141 A-B) no indican diferencias significativas de composición. Los datos descartan que sus cuerpos de base se elaborasen con bronce (Maya 1988: 141) y confirman el uso de plata posteriormente dorada. Los análisis de la capa de do- 
rado muestran el uso de una aleación con alto contenido de plata (ca. o superior al $40 \%$ ) y baja tasa de cobre (ca. $1 \%$ ), valores que reflejan el metal de base. Destaca una elevada tasa de mercurio, en una proporción superior a la observada en el torques MAA 03300. Los valores máximos de este elemento se recogen en el reverso de los discos (Tab. 2: PA25140 A y PA25141 A), aunque también se documenta en la decoración de los anversos (Tab. 2: PA25141 B).

Para intentar contrastar esta información y profundizar en la caracterización del recubrimiento áureo de hilos y glóbulos -un procedimiento hasta la fecha no documentado en la orfebrería castreña- las piezas se revisaron de forma más pormenorizada en SEM-EDX. Aunque la presencia de material de restauración limitó notablemente el trabajo, las zonas accesibles del disco n. 03298 parecen confirmar estos datos (Tab. 5; Fig. 11). Como se observó ya en otros objetos, los valores de plata recogidos con SEM-EDX en el dorado fueron inferiores a los aportados por los análisis pXRF. Aunque extraña el alto porcentaje de mercurio conservado en las piezas, no fue posible verificar con los medios empleados posibles actuaciones modernas sobre este recubrimiento, muy deteriorado en las zonas accesibles del anverso de los cuerpos de base.

En resumen, los resultados apuntan al uso de un dorado al fuego, aplicado tanto a los cuencos como a los elementos ornamentales. El que algunos de ellos hayan perdido hoy su recubrimiento probablemente llevó a indicar que los discos incluían glóbulos de oro y de plata (Escortell 1982: 84). Tanto el interés de los datos obtenidos como las limitaciones del presente estudio hacen recomendable el planteamiento de una revisión arqueométrica más pormenorizada para profundizar en el conocimiento de los procedimientos de trabajo aplicados en estas piezas.
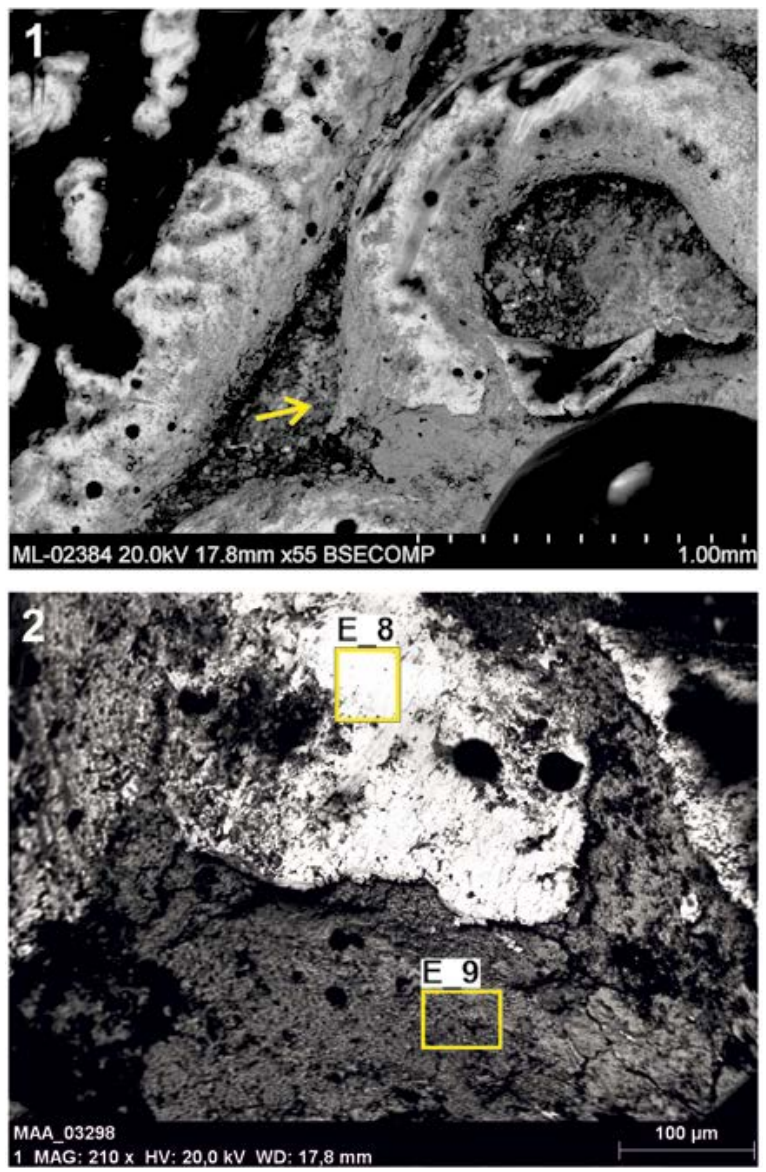

Fig. 11. Disco MAA 03298 (anverso): 1. fractura en la capa de dorado de la decoración de filigrana X55, 2. detalle de la misma zona, señalándose las áreas analizadas por energía dispersiva de rayos- $\mathrm{X}$ (EDX), X210. Las zonas más oscuras corresponden a la presencia de material de restauración (imágenes de microscopía electrónica de barrido, SEM, de electrones retrodispersados). Microlab (IH, CSIC).

\begin{tabular}{|c|c|c|l|l|c|c|c|c|c|c|c|}
\hline Invent. & Id. & Zona & \multicolumn{1}{|c|}{ Elemento } & Detalle & $\begin{array}{c}\mathbf{C u} \\
\mathbf{( \% )}\end{array}$ & $\begin{array}{c}\mathbf{A g} \\
\mathbf{( \% )}\end{array}$ & $\begin{array}{c}\mathbf{A u} \\
\mathbf{( \% )}\end{array}$ & $\begin{array}{c}\mathbf{H g} \\
\mathbf{( \% )}\end{array}$ & $\begin{array}{c}\mathbf{C l} \\
\mathbf{( \% )}\end{array}$ & Otros & Aumentos \\
\hline MAA 03298 & e1 & Anverso & Hilo (filigrana) & Superficie & -- & 12,20 & 73,84 & 13,96 & -- & $\mathrm{Al}$ & $\mathrm{X} 900$ \\
\hline MAA 03298 & e2 & Anverso & Hilo (filigrana) & Superficie & -- & 8,77 & 73,35 & 17,88 & -- & $\mathrm{Al}$ & $\mathrm{X} 900$ \\
\hline MAA 03298 & e4 & Anverso & Cuerpo base & Dorado & -- & 6,10 & 79,70 & 14,20 & -- & & X1300 \\
\hline MAA 03298 & e6 & Anverso & Cuerpo base & Mat. base & 2,12 & 76,63 & 7,89 & 4,85 & 8,51 & $\mathrm{~S}, \mathrm{Fe}$ & $\mathrm{X} 1200$ \\
\hline MAA 03298 & e8 & Anverso & Hilo (filigrana) & Superficie & -- & 7,47 & 74,85 & 17,68 & -- & & X210 \\
\hline MAA 03298 & e9 & Anverso & Hilo (filigrana) & $\begin{array}{l}\text { Interior } \\
\text { alterado }\end{array}$ & -- & 81,63 & nd & nd & 18,37 & S; Si, Al & X210 \\
\hline
\end{tabular}

Tab. 5. Algunos resultados obtenidos en el muestreo mediante microscopía electrónica de barrido por energía dispersiva de rayos-X (SEMEDX) del disco MAA 03298, considerando los elementos mayoritarios documentados. Datos normalizados y expresados en \% de peso. Mat Material; n d no documentado o por debajo de límite de detección. 


\section{DISCUSIÓN}

Las ocho piezas analizadas incluyen tres elaboradas con aleaciones de oro-plata (MAA 93671; MAA 08025 y MAA 06670), una con aleación de plata-cobre (MAA 06643), dos con aleaciones de plata-cobre doradas (MAA 03540 y MAA 03300) y otras dos con plata dorada (MAA 03298 y MAA 03299).

La revisión realizada permite incidir en algunas cuestiones de interés a nivel metodológico y tecnológico. Desde el punto de vista metodológico, la comparación de los resultados analíticos registrados sobre estos objetos mediante pXRF y SEM-EDX pone de manifiesto la necesidad de manejar con precaución los datos cuantitativos obtenidos en análisis de composición superficiales (Blakelock 2016) y la conveniencia de contrastarlos con unos muestreos pormenorizados y la aplicación de diferentes técnicas analíticas. Hay que tener en cuenta que la capacidad de penetración de la técnica SEM-EDX se limita a unas pocas micras bajo la superficie del objeto. Ello la hace más sensible que la técnica pXRF a alteraciones en los resultados producidas por fenómenos como el del enriquecimiento superficial del oro o la corrosión. Además tiene menor resolución cuantitativa. Otro factor a considerar es el tamaño del área estudiada en cada caso, que suele ser mucho más reducido en los análisis SEM-EDX y por lo tanto potencialmente más sensible a las heterogeneidades en la composición de la muestra.

En este sentido, el recurso a procedimientos no destructivos con mayor resolución analítica, capacidad de penetración en el metal y rango de escala $-\mathrm{p}$. ej. micro XRF o micro PIXE (Particle Induced $X$ ray Emission)- constituye una buena alternativa, aportando información más detallada para el estudio de aspectos como los procedimientos ornamentales -filigrana, granulado-, las técnicas de unión -soldadura- o la documentación de elementos traza (Guerra y Calligaro 2004; Troalen et al. 2014 o Valério et al. 2019).

A la espera de poder aplicar estos estudios, el trabajo desarrollado sobre las piezas del MAA aporta nuevos datos para el estudio de la tecnología orfebre de la II Edad del Hierro en el territorio de Asturias. El principal aspecto a destacar es la identificación de nuevos ejemplos de dorado por amalgama con mercurio. Esta variante de la técnica de dorado (DraymanWeisser 2000; Oddy 2000), también conocida como dorado al fuego, aprovecha la capacidad del mercurio de amalgamarse con otros materiales a temperaturas moderadas y la volatilidad de este elemento para obtener un recubrimiento de calidad con un ahorro de materia prima.

A grandes rasgos consiste en recubrir con oro la superficie del objeto, empleando una amalgama de oromercurio previamente preparada o aplicando láminas de "pan de oro" sobre una capa base de mercurio. En ambos casos, la superficie debe calentarse para lograr la evaporación del mercurio, quedando recubierta por una fina capa de oro que por lo general recibe un tratamiento de acabado por bruñido. Se suele emplear oro de ley muy alta, para aprovechar al máximo su maleabilidad. Varios autores (p. ej. Northover y Anheuser 2000) han abordado ya las diferentes opciones de ejecución del procedimiento.

Actualmente se acepta que la técnica se extendió por Europa en especial a partir de la época romana tardía, aunque sus orígenes son aún objeto de debate. Se ha considerado su surgimiento en China hacia el siglo $\mathrm{V}$ a. n. e. y su difusión posterior hacia occidente con posibles vías de transmisión mediterráneas -hipótesis predominante- o atlánticas. También se han valorado varios orígenes independientes en Europa. Su uso ha sido insuficientemente estudiado en la orfebrería antigua de la península ibérica (Perea et al. 2008; e. p.), donde al igual que en otras regiones está mejor documentado a partir de la época romana tardía y sobre todo durante el período medieval (Perea 2009; Barrio y Chamón 2010). Sobre su llegada a este territorio se han planteado varias propuestas, predominando la de su difusión por vía mediterránea en época helenística, aproximadamente desde finales del siglo IV a. n. e. (Craddock 1977: 109). Se ha valorado también una posible vía de transmisión atlántica desde las islas británicas, donde la técnica está documentada hacia el siglo I a. n. e. (Northover y Anheuser 2000), considerando otros autores que su introducción no se produjo hasta la romanización (Oddy 2000).

Más recientemente se sugirió un posible foco de origen independiente en el sur de la península ibérica a partir de la identificación de dorados al fuego en fíbulas ibéricas fechadas entre los siglos III-I a. n. e. (Perea et al. 2008: 127). Como las anteriores, esa propuesta se ha visto limitada por la escasez de estudios arqueométricos, que sigue afectando a estos estudios (Perea et al. e. p.).

Recordaremos que el uso de esta técnica en la orfebrería castreña pasó largo tiempo inadvertido, considerándose tradicionalmente como su característica básica la producción de piezas elaboradas con oro. Desde los 2000 trabajos centrados en el estudio tecnológico del torques, su tipo material más representado, destacaron la importancia del uso en esta orfebrería de procedimientos como el chapado, destinados a dotar de una apariencia áurea a piezas elaboradas con otros metales. Su aplicación se valoró, junto a otros elementos, como un posible rasgo indicador de piezas con una cronología tardía, probablemente desde mediados del siglo III a. n. e. y durante el proceso de romanización del noroeste (Perea 2003: 147-148). 
El incremento de los estudios arqueométricos sobre piezas de orfebrería castreña permitió avanzar en la caracterización de este tipo de técnicas. La identificación de mercurio en los análisis pXRF de un fragmento de torques del castro de Viladonga (Castro de Rei, Lugo), fechado entre los siglos I a. n. e - I d. n. e. (Ladra y Martinón-Torres 2009: 35-36), y de un terminal de torques sin procedencia, también conservado en el museo de este castro, vino a confirmar la aplicación de dorados al fuego. A estas piezas se sumó posteriormente un adorno espiraliforme con aro de plata dorada del castro de La Corona de Corporales (Truchas, León) (Cuesta et al. 2012: 55-56), cuyo contexto de recuperación se fechó en la primera mitad del siglo I a. n. e. (Sánchez-Palencia y Fernández-Posse 1985).

Las primeras identificaciones dieron lugar a varias hipótesis sobre la vía y el momento de llegada de la técnica a este ámbito, como la de su difusión desde la zona centro-sur de la península ibérica o por una ruta marítima atlántica desde las islas británicas. Se consideró también su incorporación en época romana o incluso su posible transmisión desde el noroeste peninsular a las islas británicas (Martinón-Torres y Ladra 2011: 195).

Ninguna de estas propuestas puede verificarse con los escasos datos disponibles y recordemos que los problemas de información contextual siguen limitando la adecuada periodización de la orfebrería castreña. En esta situación, el estudio de las piezas del MAA aumenta los argumentos a favor del uso de esta técnica en el noroeste peninsular en momentos previos al cambio de era (ca. siglo I a. n. e.). Esta fecha se integra en un período de profundas transformaciones sociales en el mundo castreño (siglo II-I a. n. e.), cuyo estudio centra buena parte de la discusión actual y durante el cual parece producirse el mayor auge de esta orfebrería (González 2006-2007: 422; Sastre 2008; Armada y García-Vuelta 2015: 378, 2018: 231-232; Parcero et al. 2017: 26, 30-31; Currás 2019: 302).

A nuestro juicio, en tanto se publican nuevas evidencias, estos datos permiten apoyar una valoración de la aplicación de esta técnica como indicador de los cambios que afectaron tanto a los sistemas de producción indígenas, como al concepto de valor y al propio significado de su orfebrería (Perea 2003: 148). Esto ocurrió principalmente partir del contacto de esas sociedades con Roma y concluyó hacia ca. finales del siglo I con la paulatina desaparición de los rasgos y tipos materiales que la caracterizaron.

\section{CONSIDERACIONES FINALES}

La colección del Museo Arqueológico de Asturias incorpora materiales que ofrecen un especial interés para el estudio de la tecnología orfebre de la II Edad del Hierro en el norte y noroeste de la península ibérica y que constituyen a la vez buenos ejemplos de los problemas que todavía afectan a su investigación. Los trabajos realizados aportan un nuevo conjunto de datos sobre unas piezas que permanecían insuficientemente estudiadas tanto a nivel formal como técnico, facilitando su mejor integración en los estudios sobre orfebrería castreña. Como ya se ha señalado, algunas de las hipótesis sugeridas deberán ser contrastadas a la luz de nueva información arqueométrica. Las dificultades encontradas en la investigación ponen de manifiesto la conveniencia de continuar avanzando en la aplicación de protocolos y técnicas de trabajo óptimas para una adecuada caracterización de estos materiales.

Recordemos también que otra parte importante de esas dificultades, especialmente desde el punto de vista interpretativo, deriva de la falta de información sobre los hallazgos. Ello evidencia la necesidad de desarrollar líneas de actuación que aporten nuevos datos sobre aspectos fundamentales, como el contexto de recuperación, la procedencia, o la "biografía reciente" de los objetos, desde su descubrimiento hasta el momento actual, temas donde la información archivística se ha demostrado de gran ayuda. Las cuestiones todavía abiertas para el estudio de las piezas del MAA constituyen buenas muestras de la labor por realizar en ese sentido, así como de la necesidad de establecer una convergencia entre todas estas actuaciones.

\section{AGRADECIMIENTOS}

Al Museo Arqueológico de Asturias por las facilidades prestadas para el estudio de los materiales.

\section{BIBLIOGRAFÍA}

Adán Álvarez, G. E. 1999: "La Comisión de Monumentos Históricos y Artísticos de Asturias y su imbricación en los Museos asturianos en el siglo XIX y principios del XX (1844-1919): el Museo Arqueológico Provincial". Boletín Anabad 49 (2):175-204.

Armada, X. L. y García-Vuelta, O. 2015: "Dating Iron Age goldwork: First direct AMS ${ }^{14} \mathrm{C}$ results from Northwestern Iberia”. Trabajos de Prehistoria 72 (2): 372-382. https://doi.org/10.3989/tp.2015.12160

Armada, X. L. y García-Vuelta, O. 2018: "Iron Age gold in Northwestern Iberia: technology, chronology and social meaning”. En R. Schwab, P. Y. Milcent, B. R. Armbruster y E. Pernicka (eds.). Iron Age Gold in Celtic Europe. Society, Technology and Archaeometry. Forschungen zur Archäeometrie und Altertumswissenchaft. Bd, 6, 1, Verlag. Marie Leidorf GmbH. Rahden/West: 321-338.

Armbruster, B. R. y Perea, A. 2000: "Macizo/hueco, soldado/fundido, morfología/tecnología. El ámbito tecnológico castreño a través de los torques con remates en doble escocia". Trabajos de Prehistoria 57 (1): 97-114. https://doi.org/10.3989/tp.2000.v57.i1.262

Barrio Martín, J. y Chamón Fernández, J. (eds.) 2010: Proyecto Dorados. Tecnología, conservación y restauración de los metales dorados me- 
dievales. Tecnología y Conservación del Patrimonio Arqueológico II, Universidad Autónoma de Madrid. Madrid.

Berrocal Rangel, L.; Martínez Seco, P. y Ruiz Triviño, C. 2002: El castiellu de Llagú. Un castro astur en los origenes de Oviedo. Principado de Asturias. Bibliotheca Archaeologica Hispana 13, Gabinete de Antigüedades de la Real Academia de la Historia. Madrid.

Blakelock, E. S. 2016: "Never judge a gold object by its surface analysis: a study of surface phenomena in a selection of gold objects from the Staffordshire hoard". Archaeometry 58 (6): 912-929. https://doi.org/10.1111/arcm.12209

Blanco Freijeiro, A. 1957: "Origen y relaciones de la orfebrería castreña". Cuadernos de Estudios Gallegos XII (36): 5-28.

Blas Cortina, M. A. de 1983: La prehistoria reciente en Asturias. Estudios de Arqueología Asturiana 1, Principado de Asturias. Oviedo.

Blas Cortina, M. A. de 1994: "El anillo áureo de tiras de la Mata l'Casare I y su localización megalítica". Madrider Mitteilungen 35: 107-122.

Blas Cortina, M. A. de 2013: "IV Milenio a. de C.: los monumentos sepulcrales del Puerto de la Cobertoria (Quirós) y el dominio de las cumbres por las sociedades neolíticas". En M. A. de Blas Cortina (ed.): De Nenderthales a Albiones. Cuatro lugares esenciales en la Prehistoria de Asturias. Real Instituto de Estudios Asturianos. Oviedo: $69-138$.

Blet-Lemarquand, M.; Da Mota, H.; Gratuze, H.; Leusch, M.; Schawb, R. 2018: "Material sciences applied to West Hallstatt gold". En R Schwab, P. Y. Milcent, B. R. Armbruster y E. Pernicka (eds.): Iron Age Gold in Celtic Europe. Society, Technology and Archaeometry. Forschungen zur Archäeometrie und Altertumswissenchaft 6 (1). Rahden/West: 101-132.

Camino Mayor, J. 1995a: "Excavaciones arqueológicas en castros de la ría de Villaviciosa: apuntes para una sistematización de la Edad del Hierro". Excavaciones arqueológicas en Asturias (1991-1994). Principado de Asturias. Oviedo: 117-126.

Camino Mayor, J. 1995b: "Pendiente". En J. Fernández León, F. Gil Sendino y M. P. García Quirós (eds.): Astures. Pueblos y culturas en la frontera del imperio romano. Gran Enciclopedia Asturiana. Gijón: 247.

Carballo Arceo, L. X. 1994: Catálogo dos materiais arqueolóxicos do museu do castro de Santa Trega: Idade do Ferro. Padroado do Monte de Santa Trega. A Guarda.

Craddock, P. T. 1977: "The composition of cooper alloys used by Greek, Etruscan and Roman civilisations 2. The Archaic, Classical and Hellenistic Greeks". Journal of Archaeological Science 4: 103-123. https://doi.org/10.1016/0305-4403(77)90058-9

Cuesta Gómez, F.; García-Vuelta, O.; Gener, M.; Montero Ruiz, I.; Murillo-Barroso, M.; Perea, A. y Renzi, M. 2012: "Técnicas de dorado en época prerromana: nuevos casos de estudio en el interior peninsular". En M. I. Días y J. L. Cardoso (eds.): Actas do IX Congresso Ibérico de Arqueometría (Lisboa 2011). Estudos Arqueológicos de Oeiras 19: 51-56. https://doi.org/10.13140/2.1.2240.9604

Currás Refojos, B. 2019: Las sociedades de los castros entre la Edad del Hierro y la dominación de Roma: estudio del paisaje del Baixo Miño. Bibliotheca Praehistorica Hispana 35, CSIC. Madrid

Diego Somoano, C. 1960-1961: "La colección 'Soto Cortés' de Labra, Cangas de Onís". Boletín del Real Instituto de Estudios Asturianos XL, XLI y XLII: 269-291; 440-452; 125-140.

Drayman-Weisser, T. (ed.) 2000: Gilded Metals. History, technology and conservation. Archetype Publications. Londres.

Escortell Ponsoda, M. 1982: Catálogo de las Edades de los Metales del Museo Arqueológico de Oviedo. Principado de Asturias. Oviedo.

Fernández de Córdoba Pérez, J. A. 2017: "El Museo Arqueológico de Asturias". Boletín del Museo Arqueológico Nacional 35: 597-612.

Fernández Moreno, J. J.; García Alonso, B.; Álvarez García, R. y Fernández González, M. A. 2018: "Los discos de oro del Museo Arqueológico de Asturias: algunas observaciones sobre la orfebrería prehistórica”. Zephyrus LXXXII: 65-92. http://dx.doi.org/10.14201/zephyrus2018826592

García-Vuelta, O. 2007: Orfebrería castreña en el Museo Arqueológico Nacional. Ministerio de Cultura. Madrid.

García-Vuelta, O. 2017: "La orfebrería castreña del entorno de Villamayor (Piloña) a la luz de nueva documentación". Boletín del Museo Arqueológico Nacional 36: 169-190.
García-Vuelta, O. 2018: "Estudios documentales e investigación de la orfebrería castreña en Asturias: aportaciones sobre las piezas de la colección Soto Cortés". En A. Carretero Pérez, C. Papí Rodes y G. Ruiz Zapatero (eds.): Actas del V congreso internacional de Historia de la Arqueología IIV Jornadas de Historiografia SEHA-MAN: Arqueología de los Museos: 150 años de la creación del Museo Arqueológico Nacional (Madrid 2017): 1.397-1.410. Madrid.

García-Vuelta, O.; Fernández-Piloñeta, X. y Álvarez Peña, A. 2016: "Ayalgues n'Asturies. Sobre afayos antiguos de pieces d'oru nel conceyu d'Ayer". Asturies 36: 28-31.

García-Vuelta, O. y Montero Ruiz, I. 2007: “Aportaciones analíticas sobre orfebrería castreña: problemas de caracterización en piezas de la colección del Museo Arqueológico Nacional (Madrid)". Conimbriga XLVI: 89-115.

Garriga y Palau, A. F. J. 1915: Actas y Tareas de la Comisión de Monumentos Históricos y Artísticos de la Provincia de Oviedo. Desde 1874 a 1912. Imp. Flórez, Gusano y Cia. Oviedo.

González Ruibal, A. 2006-2007: Galaicos. Poder y comunidad en el Noroeste de la Península Ibérica (1200 a.C.-50 d.C.). Brigantium 18-19. A Coruña.

Guerra, M. F. y Calligaro, T. 2004: "Gold traces to trace gold". Journal of Archaeological Science 31: 1.199-1.208. https://doi.org/10.1016/j.jas.2002.05.001

Guerra, M. F. y Tissot, M. I. 2015: "Bronze Age and Iron Age gold torcs and earrings from the Iberian Atlantic Façade: a non-invasive multianalytical approach to the characterisation of the alloys and the corrosión". X-ray Spectrometry 45 (1): 5-13. https://doi.org/10.1002/xrs.2628

Hartmann, A. 1982: Prähistorische Goldfunde aus Europa II. Spektralanalytische Untersuchungen und deren Auswertung. Studien zu den Anfängen der Metallurgie 5, Gebr Mann Berlag. Berlín.

Hernando, A. 1983: "La orfebrería durante el Calcolítico y el Bronce Antiguo en la Península Ibérica". Trabajos de Prehistoria 40: 85-138.

Hevia Gómez, P. 1995: "Cadena de eslabones entrelazados". En J. Fernández León, F. Gil Sendino y M. P. García Quirós (eds.): Astures. Pueblos y culturas en la frontera del imperio romano. Gran Enciclopedia Asturiana. Gijón: 269.

Ladra, L.; Armada, X. L. y Martinón Torres, M. 2014: "Ourivería galaica no Museo das Mariñas: a Colección Seoane". Anuario Brigantino 37: 25-52.

Ladra, L. y Martinón-Torres, M. 2009: "Variacións tecnolóxicas e preferencias culturais: estudo analítico dos ouros do castro de Viladonga". Croa 19: 32-43.

López Cuevillas, F. 1951: Las joyas castreñas. CSIC. Madrid.

Mac White, E. 1951: Estudios sobre las relaciones atlánticas de la Península Hispánica en la Edad del Bronce. Seminario de Historia Primitiva del Hombre. Madrid.

Martinón-Torres, M. y Ladra, L. 2011: "Orígenes del dorado por amalgama: aportaciones desde la orfebrería protohistórica del Noroeste de la Península Ibérica". Trabajos de Prehistoria 68 (1): 187-198. https://doi.org/10.3989/tp.2011.11066

Martinón-Torres, M. y Ladra, L. 2018: “A ourivería prehistórica no Museu Provincial de Lugo: una aproximación desde a química". En Balseiro, A. (ed.): A colección de Ourivería Antiga do Museo Provincial de Lugo. Diputación. Provincial de Lugo. Lugo: 46-58.

Maya González, J. L. 1988: La cultura material de los castros asturianos. Estudios de la Antigüedad, 4-5, Univ. Autónoma de Barcelona. Bellaterra.

Maya González, J. L. y Cuesta Toribio, F. (eds.), 2001: El castro de la Campa Torres. Periodo prerromano. VTP Editorial/Ayto. de Gijón. Gijón.

Monge Soares, A. M.; Valério, P.; Silva, R. J. C.; Alves, A. L. C. y Araújo, M. F. 2017: "The Fortios disks revisited". Trabajos de Prehistoria 74 (1): 181-184. https://doi.org/10.3989/tp.2017.12190

Monteagudo García, L. 1952: "Torques castreños de alambres enrollados". Archivo Español de Arqueología XXV (86): 287-296.

Montero Ruiz, I. y Rovira Llorens, S. (1991): "El oro y sus aleaciones en la España prerromana”. Archivo Español de Arqueología 64 (163164): 7-21. https://doi.org/10.3989/aespa.1991.v64.496

Northover, P. y Anheuser, K. 2000: "Gilding in Britain: Celtic, Roman and Saxon". En T. Drayman-Weisser (ed.): Gilded Metals. History,

Trab. Prehist., 77, N. ${ }^{\circ}$ 1, enero-junio 2020, pp. 163-183, ISSN: 0082-5638

https://doi.org/10.3989/tp.2020.12252 
technology and conservation. Archetype Publications. Londres: 109121.

Oddy, A. 2000: "A history of gilding with particular reference to statuary”. En T. Drayman-Weisser (ed.): Gilded Metals. History, technology and conservation. Archetype Publications. Londres: 1-19.

Parcero Oubiña, C.; Armada, X. L. y Ayán Vila, X. 2017: "Castros en la escalera: el noroeste entre la normalidad y la indiferencia”. En S. Celestino (ed.): La protohistoria de la Península Ibérica. Itsmo. Madrid: $815-878$

Perea, A. 1991: Orfebrería prerromana. Arqueología del oro. Caja de Madrid. Madrid.

Perea, A. 2003: "Los torques castreños en perspectiva". Brigantium 14: 139-149.

Perea, A. (ed.) 2009: El tesoro visigodo de Torredonjimeno. CSIC. Madrid.

Perea, A.; García-Vuelta, O. y Fernández Freire, C. 2010: El Proyecto $A U$. Estudio arqueométrico de a producción de oro en la Península Ibérica. Bibliotheca Praehistorica Hispana XXVII, CSIC. Madrid.

Perea, A.; García-Vuelta, O. y Montero Ruiz, I. (e. p.): "Mercurio en la producción orfebre peninsular: perspectivas tecnológicas y arqueométricas”. En M. Zarzalejos, P. Hevia y L. Mansilla (eds.): "El 'oro rojo' en la Antigüedad. Perspectivas de investigación sobre los usos $y$ aplicaciones del cinabrio entre la Prehistoria y el fin del mundo antiguo". Colección Arte y Humanidades, UNED. Madrid. ISBN: 978-84-362-7593-3.

Perea, A.; Montero Ruiz, I. Gutiérrez, P. C. y Climent-Font, A. 2008: "Origen y trayectoria de una técnica esquiva: el dorado sobre metal". Trabajos de Prehistoria 65 (2): 117-130. https://doi.org/10.3989/tp.2008.08006

Perea, A. y Sánchez-Palencia Ramos, F. J. 1995: Arqueología del oro astur. Orfebrería y Minería. Caja de Asturias. Oviedo.

Pérez Outeiriño, B. 1982: De Ourivesaria castrexa. 1. As Arracadas. Boletín Auriense Anexo 1, Museo Arqueolóxico Provincial de Ourense. Orense.

Pingel, V. 1992: Die Vorgeschichtlichen goldfunde der Iberischen Halbinsel. Madrider Forschungen, 17, Walter de Gruyter. Berlín-Nueva York.

Reist Stark, J. y Reist Smith, J. 2007: Classical loop-in-loop chains \& their derivatives. A\&C Black. Londres.

Rodríguez Álvarez, R. 2002: Dos bibliófilos asturianos del siglo XIX. D. Felipe de Soto Posada y D. Sebastián de Soto Cortés. Real Instituto de Estudios Asturianos. Oviedo.
Rovira Llorens, S. y Montero Ruiz, I. 2018: "Proyecto 'Arqueometalurgia de la Península Ibérica' (1982-2017)”. Trabajos de Prehistoria 75 (2): 223-247. https://doi.org/10.3989/tp.2018.12213

Sanchez-Palencia Ramos, F. J. y Fernández-Posse, M. D. 1985: La Corona y el Castro de Corporales I. Truchas (León). Campañas de 1978 a 1981. Excavaciones arqueológicas en España 141, Ministerio de Cultura. Madrid.

Sastre Prats, I. 2008: "Identity and conflict: Iron Age warfare in the Iberian Northwest". Current Anthropology 49 (6): 1.021-1.051. https://doi.org/10.1086/529423

Silva, A. C. F da 2007: A Cultura Castreja no noroeste de Portugal. Paços de Ferreira. 1. ${ }^{\text {a }}$ ed. 1986.

Somoza García Sala, J. 1971: Gijón en la historia general de Asturias. Ed. Facsímil Flores. Gijón. 1. a ed. 1908.

Troalen, L. G.; Tate, J. y Guerra, M. F. 2014. "Goldwork in ancient Egypt: workshop practices at Qurneh in the 2nd Intermediate Period". Journal of Archaeological Science 50: 219-226. https://doi.org/10.1016/j.jas.2014.07.010

Tuñón Quirós, E. 1858: Memoria sobre la guerra que los romanos hicieron en Asturias. Est. Tipográfico Francisco Pedregal. Oviedo.

Valério, P.; Silva, R. J. C.; Soares, A. M. M.; Araújo, M. F.; Baptista, L. y Calvo, E. 2019: "Microanalytical study of ancient gold jewelry: Mediterranean impact on the Early Iron Age technology in Southwestern Iberia". Microscopy and Microanalysis 25 (4): 1.061-1.073. https://doi.org/10.1017/S1431927619014582

Villa Valdés, A. 2004: "Orfebrería y testimonios metalúrgicos en el castro de Chao Samartín (Grandas de Salime, Asturias): estudio cronoestratigráfico (siglos IV a.C. a II d.C.)". En A. Perea, I. Montero Ruiz y O. García-Vuelta (eds.): Tecnología del oro antiguo: Europa y América. Anejos de Archivo Español de Arqueología XXXII, CSIC. Madrid: 253-264.

Villa Valdés, A. (ed.) 2009: Museo Castro de Chao Samartín (Grandas de Salime, Asturias). Catálogo. Gobierno del Principado de Asturias, Consejería de Cultura y Turismo. Siero, Asturias.

Villa Valdés, A. 2010: "El oro en la Asturias antigua: beneficio y manipulación de los metales preciosos en torno al cambio de Era". En J. A. Fernández Tresguerres (ed.): Oro y Cobre, minería y metalurgia en la Asturias prehistórica y antigua. Real Instituto de Estudios Asturianos. Oviedo: 83-125.

Villa Valdés, A. 2019: "Contextos arqueológicos para la orfebrería protohistórica de Asturias”. Boletín del Museo Arqueológico Nacional 38: $27-44$. 